\title{
Cellular and molecular actors of myeloid cell fusion: podosomes and tunneling nanotubes call the tune
}

\author{
Ophélie Dufrançais ${ }^{1} \cdot$ Rémi Mascarau $^{1,2,3} \cdot$ Renaud Poincloux $^{1} \cdot$ Isabelle Maridonneau-Parini ${ }^{1,2}$. \\ Brigitte Raynaud-Messina ${ }^{1,2,3} \cdot$ Christel Vérollet $^{1,2,3}$
}

Received: 28 January 2021 / Revised: 25 May 2021 / Accepted: 5 June 2021 / Published online: 23 July 2021

(c) The Author(s) 2021

\begin{abstract}
Different types of multinucleated giant cells (MGCs) of myeloid origin have been described; osteoclasts are the most extensively studied because of their importance in bone homeostasis. MGCs are formed by cell-to-cell fusion, and most types have been observed in pathological conditions, especially in infectious and non-infectious chronic inflammatory contexts. The precise role of the different MGCs and the mechanisms that govern their formation remain poorly understood, likely due to their heterogeneity. First, we will introduce the main populations of MGCs derived from the monocyte/macrophage lineage. We will then discuss the known molecular actors mediating the early stages of fusion, focusing on cell-surface receptors involved in the cell-to-cell adhesion steps that ultimately lead to multinucleation. Given that cell-to-cell fusion is a complex and well-coordinated process, we will also describe what is currently known about the evolution of F-actin-based structures involved in macrophage fusion, i.e., podosomes, zipper-like structures, and tunneling nanotubes (TNT). Finally, the localization and potential role of the key fusion mediators related to the formation of these F-actin structures will be discussed. This review intends to present the current status of knowledge of the molecular and cellular mechanisms supporting multinucleation of myeloid cells, highlighting the gaps still existing, and contributing to the proposition of potential disease-specific MGC markers and/or therapeutic targets.
\end{abstract}

Keywords Cell-to-cell fusion · Adhesion · Osteoclasts (OCs) $\cdot$ Multinucleated giant cells (MGCs) $\cdot$ Podosomes $\cdot$ Tunneling nanotubes (TNTs)

Ophélie Dufrançais and Rémi Mascarau contributed equally to this work, Brigitte Raynaud-Messina and Christel Vérollet contributed equally to this work.

Brigitte Raynaud-Messina

raynaud@ipbs.fr

$\triangle$ Christel Vérollet

verollet@ipbs.fr

1 Institut de Pharmacologie et Biologie Structurale, IPBS, Université de Toulouse, CNRS, UPS, Toulouse, France

2 International Associated Laboratory (LIA) CNRS "IM-TB/HIV" (1167), Toulouse, France

3 International Associated Laboratory (LIA) CNRS "IM-TB/HIV" (1167), Buenos Aires, Argentina

\section{Introduction}

The capacity of cells to fuse and form syncytia or multinucleated cells is evolutionarily conserved among eukaryotes. Cell-to-cell fusion is an essential process during fertilization (fusion of sperm and egg), formation of the placenta (fusion of trophoblast cells), and formation of skeletal muscle (fusion of myoblasts into myotubes) [1]. One of the cell types that can undergo cell-to-cell fusion is the macrophage, which has high fusogenic properties. Indeed, macrophages have the ability to fuse under both physiological and pathological conditions, leading to the formation of multinucleated giant cells (MGCs). The most intensively studied MGCs derived from macrophages are osteoclasts (OCs), which are the exclusive bone-resorbing cells essential for bone homeostasis. Many other MGC subtypes have been described in pathological lesions, especially in infectious and non-infectious chronic inflammatory conditions. These different types of MGCs share common mechanisms of 
formation but also display unique properties $[2,3]$ that will be detailed in this review. However, MGCs remain difficult to characterize and classify because their phenotypes vary depending on their environment, the nature of the fusogenic stimuli [4-6], and their function [2, 7].

The formation of MGCs by myeloid cell fusion is a multi-step process that is spatio-temporally regulated. First, cells need to acquire fusion competence, which is under the control of both exogenous stimuli and endogenous signaling pathways. This activation then triggers adhesion of the fusion-competent cells to a permissive substrate, cell motility, cell-to-cell interactions, and finally membrane fusion [3]. Here, we will describe the cellular structures and the molecular mechanisms used by myeloid cells to adhere and fuse with each other or with other cell types. In particular, we will review the diversity of the F-actin-based structures involved in macrophage fusion: podosomes, podosomerelated zipper-like structures, and tunneling nanotubes (TNTs). In this context, the potential localization and role of the main molecular actors already described in the fusion process will be discussed.

\section{Different types of multinucleated giant cells from the monocytic lineage}

In addition to bone-resorbing OCs, there are different types of MGCs with a monocyte/macrophage origin. We decided here to focus on the three best-characterized MGCs to date: the foreign body giant cells (FBGCs) formed in response to macroscopicorganic and inorganic materials, Langhans giant cells, generated in response to microbial infection, and MGCs induced by HIV-1 infection. There is also evidence suggesting that macrophages might fuse with non-myeloid cells, such as somatic cells [8], tumor cells [9, 10] or HIV1-infected T lymphocytes [11, 12]. For clarification, we will use the term 'homotypic' when fusion occurs between cells of the same cell type (e.g. between two macrophages or two OC precursors) and 'heterotypic' when fusion occurs between different cell types. To account for the complexity of the fusion processes, we will also discuss the possibility of fusion between cells having a common origin but being at different stages of differentiation, in particular in the case of fusion of OC precursors [13, 14].

\section{Homotypic fusion}

OCs are the unique type of myeloid-derived MGCs that form under physiological conditions. They are the exclusive bone-resorbing cells and, together with bone-synthesizing osteoblasts and osteocytes, they constitute the major actors in bone remodeling. OCs originate from the fusion of monocytic precursors, mainly under the control of Macrophage
Colony-Stimulating Factor (M-CSF) and Receptor Activator of Nuclear Factor- $\kappa B$ Ligand (RANK-L) [15-17]. RANK-L binding to its receptor leads to the activation of the master transcription regulator of osteoclastogenesis, the Nuclear Factor of Activated T Cells 1 (NFATc1) and the increased expression of resorption-related genes [18]. OC attachment to bone is mediated by a specific structure, the sealing zone, which is composed of a dense array of inter-connected F-actin structures called podosomes [16, 19-21] (see "Role of podosomes and zipper-like structures in myeloid cell fusion" below). The sealing zone participates in the creation of a confined resorption environment, where protons and osteolytic enzymes are secreted [19]. Recent studies in vivo show that mature OCs are most often formed by sequential fusion events with mononucleated OC precursors, suggesting the addition of one nucleus at a time [22, 23]. This progressive process involves fusions between heterogeneous myeloid precursors, whose phenotype could evolve according to the number of nuclei [13, 24, 25]. The formation and function of OCs are tightly controlled in vivo, since dysregulation of OC differentiation and/or function may lead to bone defects, such as osteopetrosis or osteoporosis. Although the specific role of multinucleation in the osteolytic process remains unclear, it has been proposed that cell-to-cell fusion allows OCs to cover a larger bone area to enhance bone resorption activity. In support of this hypothesis, mononuclear or poorly fused OCs degrade bone tissue less efficiently than giant and multinucleated OCs [26-29]. On the other hand, in some pathological conditions such as Paget's disease, bone fragility observed in patients are associated with a strong increase in the number of nuclei per OC but also in OC number and responsiveness to osteoclastogenic signals, among other modified parameters [30]. In addition, infection of OCs with several pathogens (e.g. Staphylococcus aureus and HIV-1) leads to an increase in their ability to fuse and degrade the bone matrix [31-34]. However, the functionality of some proteins involved in OC fusion in vitro does not systematically correlate with altered OC differentiation or bone phenotype in vivo, at least under physiological conditions $[35,36]$. These discrepancies between in vitro and in vivo observations will be discussed throughout this review.

FBGCs commonly form at the tissue/material interface of implanted medical biomaterials or in tissues where foreign particles or organisms are too large to be phagocytosed $[4,7]$. In response to these exogenous materials, acute and chronic inflammation occurs in a sequential fashion, leading to a local increase of interleukin-4 (IL-4) and interleukin-13 (IL-13). In vitro, IL-4- or IL-13- induced FBGC-like cells may have up to one hundred nuclei dispersed throughout the cytoplasm [37]. These MGCs exhibit specific cytokine secretion profiles and maintain some macrophage surface expression markers, whereas the CD14 monocyte marker 
is down-modulated, resulting in giant cells with a phenotype distinguishable from that of unfused macrophages and other MGCs [38-41]. This phenotype is dependent on material surface chemistry [42]. Although the exact role of FBGCs remains unclear, they are able to phagocytise large and complement-opsonized materials more efficiently than their unfused precursors, and their formation in vivo accompanies the elimination of complement-amyloid deposits [43, 44], suggesting that MGCs are more than the sum of their mononucleated macrophage counterparts.

MGCs are also associated with pathological contexts such as lesions of Langerhans cell histiocytosis [45] and granuloma disorders including sarcoidosis [46], helminthic schistosomiasis [47], and microbial infections. The first granuloma was described by Langhans in the lungs in response to infection by Mycobacterium tuberculosis (Mtb), the primary causative agent of tuberculosis [2]. In the early stages of infection, the granuloma consists of a compact and organized aggregate of epithelioid cells (highly specialized, differentiated macrophages) surrounded by a ring of lymphocytes. At later stages, the granuloma develops a fibrous capsid that isolates the core of infected macrophages, reduces vascularization, and thus limits bacilli spread. The plasticity of macrophages is essential for granuloma maturation and dynamics. In particular, macrophages can form MGCs or differentiate into foam cells, characterized by an accumulation of lipids [48]. It is generally accepted that these MGCs, called Langhans giant cells, result from cell-to-cell fusion under the control of inflammatory cytokines. However, it has been proposed that they can also result from defects in cell division $[6,49,50]$. In vitro, the combination of GM-CSF exposition with IFN- $\gamma$ or IL-3 is sufficient to induce the formation of Langhans giant-like cells with approximately 15 nuclei arranged in a circular pattern [37]. Moreover, within a human in vitro model of granuloma, the fusion of MGCs can be triggered by mycobacterial envelope glycolipids [51]. It remains unresolved whether these MGCs are beneficial or detrimental to the host, as granuloma aggregates restrain Mtb dissemination but do not eliminate all bacilli, promoting their persistence [52]. Several studies have made it possible to decipher their dual roles. In granuloma models, infection with a virulent strain of Mtb induces large MGCs that can no longer mediate bacterial uptake, whereas infection with less virulent species results in MGCs of smaller size but retaining phagocytic capabilities [53]. Moreover, following infection with $\mathrm{Mtb}$, macrophages produce high levels of nitric oxide that drive the transformation of macrophages into giant cells permissive for bacilli persistence [54]. On the other hand, MGCs in tuberculous lymph-nodes highly express extracellular matrix-degrading enzymes, which may promote tissue damage [55]. It is clear that MGCs play a central role in the maintenance of chronic infection and associated tissue damage, however, their role during Mtb infection needs to be further clarified.

Virus-induced fusion of macrophages and more generally of myeloid cells, to our knowledge, has only been studied in the context of HIV-1 infection. Membrane fusion is a mechanism commonly used by several families of enveloped viruses (e.g., Herpesviridae, Paramyxoviridae, Flaviridae, Retroviridae or Coronaviridae) to enter target cells. This process is mediated by fusogenic proteins of the viral envelopes. During productive infection, the host cell expresses new viral envelope proteins at its plasma membrane, which are able to bind to their receptors on neighboring cells, leading to cell-to-cell fusion and thus virus-induced syncytium formation [56-58]. Myeloid cells, particularly macrophages, are an important target for HIV-1, and HIV-1-induced MGC formation is considered a hallmark of macrophage infection. The fusion mechanism is dependent on the interaction between the viral protein gp120 and its receptor CD4 [59]. It can also be supported by another viral protein, Nef, which modulates the organization of the F-actin cytoskeleton of macrophages (i.e. podosomes) favoring macrophage fusion $[60,61]$. Importantly, this phenomenon, which is observed in vitro, is relevant in vivo, as many reports have shown the presence of HIV-positive MGCs in several tissues from infected patients, notably in secondary lymphoid organs [62], gut-associated lymphatic tissue [63], and brain [64]. Further histological analyses confirmed the myeloid origin of these MGCs. OCs have also been identified as cell targets for HIV-1, and their multinucleation and function are exacerbated after infection [31, 32]. HIV-1-induced MGCs are highly virus productive, present strong differences in their cytokine profiles, and have exacerbated migration capabilities, which likely contribute to viral dissemination in many host tissues [11, 12, 60, 65-67]. They have also been proposed to play a role in viral persistence by acting as virus reservoirs since they are long-lived cells that are resistant to virus-induced cytotoxicity, cell host restriction, $\mathrm{CD} 8^{+} \mathrm{T}$ lymphocyte-mediated killing, and some antiretroviral therapies [68-73].

\section{Heterotypic fusion}

Myeloid cells are able to fuse with poorly fusion competent cells. Among the numerous cases of heterotypic fusion that can occur under pathological conditions, we will only discuss here the fusion of myeloid-derived cells with HIV1 -infected $\mathrm{T}$ lymphocytes. It is important to notice that HIV-1 infection does not trigger efficient homotypic fusion between CD4 T cells despite the fact that they express the viral fusogenic protein gp120 [11, 67, 74].

In the context of HIV-1, MGCs can arise from infection by cell-free particles (see section above) but also from the initial heterotypic fusion between infected $\mathrm{T}$ lymphocytes 
and macrophages, followed by subsequent fusions with surrounding uninfected macrophages [12]. This happens for macrophages, OCs, and dendritic cells, but not for monocytes [31, 74-76]. Interestingly, dendritic cell maturation induced by lipopolysaccharide (LPS) stimulation inhibits this fusion process [74], suggesting that activation and polarization of myeloid cells could modulate their fusogenic capacities. Although not formally detected in vivo, these heterotypic fusion events are thought to play a crucial role in the formation of infected MGCs, especially in tissues where myeloid and $\mathrm{T}$ cells are abundant, such as secondary lymphoid organs [12, 31, 62]. Consistent with this hypothesis, in vivo studies have shown that lymphoid tissue-resident macrophages of Simian Immunodeficiency Virus (SIV)infected macaques contain T-cell markers and viral nucleic acids originating from infected $T$ cells $[77,78]$. The lack of formal evidence for the existence of these HIV-induced heterokaryons in vivo could be explained by the fact that, in vitro, these lymphocyte-monocyte cells retain a myeloid phenotype and rapidly downregulate $\mathrm{T}$ cell markers [79]. The opposite mechanism (i.e. fusion of infected myeloid cells with uninfected $\mathrm{T}$ cells) has also been proposed [80], but recent studies suggest that myeloid cells mainly transmit HIV-1 to target $\mathrm{T}$ cells through the formation of transient virological synapses without cell-to-cell fusion [81-83]. Many questions remain unanswered regarding the future of the lymphocyte/macrophage heterokaryons, such as the persistence and functionality of lymphocyte-derived nuclei.

Table 1 Molecular actors involved in myeloid cell fusion and their localization

\begin{tabular}{|c|c|c|c|}
\hline Protein & Role in myeloid cell fusion & Localization to F-actin structures & References \\
\hline DC-STAMP & Involved in $\mathrm{OC}$ and $\mathrm{FBGC}$ fusion in vitro and in vivo & Localizes on TNT between OC precursors & {$[96,99,100,107]$} \\
\hline OC-STAMP & $\begin{array}{l}\text { Involved in OC and FBGC fusion in vitro } \\
\text { Bone defects in KO mice in periodontitis model }\end{array}$ & n.d & {$[33,109,110]$} \\
\hline Siglec-15 & Involved in $\mathrm{OC}$ fusion in vitro and in vivo & n.d & [114-116] \\
\hline Integrins & $\begin{array}{l}\text { Involved in OC and FBGC fusion in vitro } \\
\text { Essential for bone homeostasis in physiological condi- } \\
\text { tions } \\
\text { Bone defects in KO mice under pathological condi- } \\
\text { tions }\end{array}$ & $\beta 2$ and $\beta 3$ localize in OC Zipper-Like-Structures & {$[124-137]$} \\
\hline CD44 & $\begin{array}{l}\text { Involved in OC formation in vitro } \\
\text { Non essential for bone homeostasis in physiological } \\
\text { conditions } \\
\text { Bone phenotype in KO mice under pathological } \\
\text { conditions }\end{array}$ & Localizes to podosomes cores, especially in OC & {$[127,140-142]$} \\
\hline $\operatorname{SIRP} \alpha$ & $\begin{array}{l}\text { Involved in macrophage and } \mathrm{OC} \text { fusion in vitro and } \\
\text { in vivo }\end{array}$ & Localizes in FBGC Zipper-Like-Structures & {$[146-156]$} \\
\hline CD47 & Ligand of SIRP $\alpha$ & n.d & $\begin{array}{l}{[145,146,149} \\
154,157,158]\end{array}$ \\
\hline CD36 & $\begin{array}{l}\text { Involved in FBGC fusion } \\
\text { Role in OC fusion unclear }\end{array}$ & $\begin{array}{l}\text { Localizes to lamellipodia and cell contact zones in } \\
\text { FBGC }\end{array}$ & {$[152,157,159]$} \\
\hline Tetraspanins & $\begin{array}{l}\text { CD9 and CD81 inhibit MGC formation in vitro and } \\
\text { in vivo } \\
\text { Role in OC fusion unclear }\end{array}$ & n.d & {$[162-165]$} \\
\hline E-cadherin & Involved in $\mathrm{OC}$ and $\mathrm{FBGC}$ fusion & $\begin{array}{l}\text { Accumulates and form complexes with catenins at } \\
\text { sites of cell contact in FBGC Zipper-Like-Structures }\end{array}$ & {$[42,169-171]$} \\
\hline Connexins & & & {$[173-180]$} \\
\hline $\mathrm{Cx}-43$ & $\begin{array}{l}\text { Involved in OC fusion in vitro } \\
\text { In vivo bone phenotype unclear }\end{array}$ & $\begin{array}{l}\text { Localizes in gap junctions between FBGC } \\
\text { Localizes at the tip of TNT between HIV-infected } \\
\text { macrophages }\end{array}$ & \\
\hline $\mathrm{Cx} 37$ & Involved in $\mathrm{OC}$ fusion in vitro and in vivo & & \\
\hline Syncytins & $\begin{array}{l}\text { Drive the fusion of plasma membranes lipid bilayers } \\
\text { Involved in fusion of OC and FBGC (early stages) } \\
\text { in vitro }\end{array}$ & $\begin{array}{l}\text { Localize at podosomes and filopodia in OC } \\
\text { Concentrate at sites of cell contacts between fusing } \\
\text { OC }\end{array}$ & {$[13,22,34]$} \\
\hline
\end{tabular}

$C x$ connexin; $C D$ cluster of differentiation; $D C$-STAMP dendritic cell-specific transmembrane protein; $F B G C$ foreign-body giant cell; $H I V$ human immunodeficiency virus; $I L$ interleukin; $K O$ knock-out; $M G C$ multinucleated giant cell; n.d. not defined; $O C$ osteoclast; $O C$-STAMP osteoclast stimulatory transmembrane protein; Siglec-15 sialic acid binding Ig-like lectin 15; SIRP $\alpha$ signal regulatory protein alpha; TNT tunneling nanotubes; $Z L S$ zipper-like structures 


\section{Molecular actors involved in cell-to-cell fusion}

Some of the molecular actors involved in the mechanisms of myeloid cell fusion have been identified in OCs. Here we will focus on the cell surface proteins (see Table 1 and Fig. 1) that are involved in OC fusion. We will discuss their implications for cell-to-cell adhesion prerequisite for fusion, and we will extend their role to other types of myeloid cell fusion, mainly the formation of FBGCs. Indeed, most of the actors described in this paragraph are "helper" cell surface proteins required to initiate the fusion process, essentially involved in recognition, rapprochement or adhesion of the two cell partners. The only factors clearly described as fusogenic proteins inducing the merging of the two membranes are the syncytins, that will be discussed at the end of this paragraph.

\section{Master cell surface regulators involved in OC fusion}

One of the master regulators of osteoclastogenesis is Dendritic Cell Stimulatory Transmembrane Protein (DCSTAMP) [84]. First identified as a dendritic cell surface protein, it is shared by other cells of the monocytic lineage, including OCs [85, 86]. Knock-down of this molecule abrogates FBGC and OC fusion both in vitro and in vivo, and DC-STAMP-deficient mice manifest a mild osteopetrotic

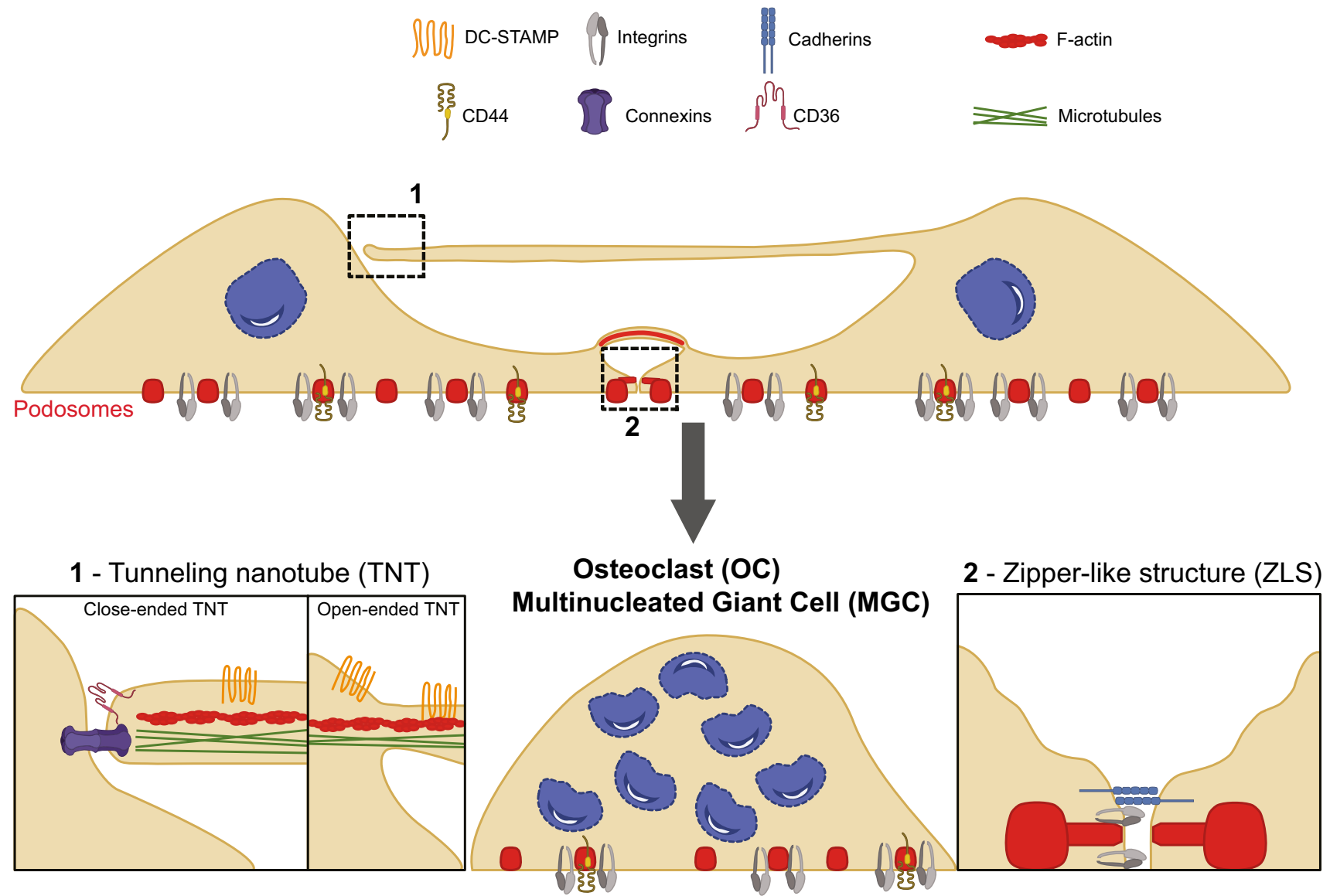

Fig. 1 Schematics representing F-actin cellular structures and potential localization of fusion mediators on these structures during the formation of multinucleated giant cells (MGCs). In this model, the main F-actin-based structures involved in the fusion process of myeloid cells are presented: tunneling nanotubes (TNTs, insert 1) likely participate in the early stages of cell-to-cell fusion, while zipper-like structures (insert 2) stabilize adhesion between multinucleated cells in the late stages, all these structures leading to MGC formation. For more clarity, we have indicated on the figure only the proteins involved in fusion localized at these structures, the identity and the role of the other proteins being detailed in Table 1. In addi- tion to the transport of proteins (i.e. proteins involved in the fusion process such as DC-STAMP) between OC precursors, TNTs could either be closed-ended TNTs where gap junction proteins (i.e. Connexin-43) and CD36 localize, or thick open-ended TNTs containing both F-actin and microtubules and aiming to mix the cytoplasm of the two cell partners. Podosomes are F-actin adherent structures present in mononucleated macrophages and MGCs. Integrins and CD44 are involved in MGC fusion and localize to the peripheral ring and to the actin core of podosomes, respectively. Podosomes could evolve into zipper-like structures (insert 2) in which adhesion proteins such as integrins and cadherins would favor strong junctions between MGCs 
phenotype associated with a lack of multinucleated OCs [84, 87, 88]. The DC-STAMP ligands are still unknown. It has been shown that the immunoreceptor tyrosine-based inhibitory motif (ITIM) on the cytoplasmic tail of DC-STAMP controls osteoclastogenesis by triggering a signaling pathway through the NFATc1/Ca ${ }^{2+}$ axis [89]. Moreover, DCSTAMP expression is under the influence of the RANKL/ NFATc1 and STAT6/STAT-1 axes, in OCs and FBGCs respectively [35, 90-92]. Although some of the results need further investigation, and will likely depend on the experimental model used, in freshly isolated human monocytes, DC-STAMP ${ }^{\text {high }}$ cells seem to be the primary precursors of OCs. Surprisingly, the surface expression of this molecule decreases during the early stages of OC differentiation [89, 93, 94]. Moreover, Hobolt-Pedersen et al. correlated the heterogenous expression and cell surface localization of DC-STAMP along with CD47 and syncytin-1 (see below for the role of these molecules in myeloid cell fusion) with the selection of the cell partner and frequency of the fusion process [25]. While a possible transport of DC-STAMP by TNTs has been proposed [95] and will be discussed later (see "Role of podosomes and zipper-like structures in myeloid cell fusion"), the underlying mechanism linking DCSTAMP and cell-to-cell fusion remain unclear.

OC stimulatory transmembrane protein (OC-STAMP) shows similarities with DC-STAMP $[35,96]$. This transmembrane protein is induced during OC differentiation and is essential for the initial steps of cell-to-cell fusion and in vitro bone resorption activity $[35,97]$. In contrast to DCSTAMP-KO mice, OC-STAMP-KO mice do not present any significant bone defects $[35,97]$. However, in the ligatureinduced periodontitis model, bone resorption is reduced in KO mice compared to $w t$ [98]. OC-STAMP is also required for FBGC formation both in vitro and in vivo $[35,99]$ and is under the control of the STAT6/STAT1 signaling axis [91]. It is noticeable that although both proteins are essential for osteoclastogenesis, they are not interchangeable but instead cooperate to promote cell-to-cell fusion [35, 100]. Moreover, both OC- and DC-STAMP-deficient cells retain the ability to fuse with $w t$ cells, suggesting that fusion is induced through a heterologous interaction between a founder and a fusion-competent cell. This new concept of heterogeneity in fusion competence should be considered in the context of heterologous fusion between a macrophage and another cell.

Another cell-surface receptor involved in OC differentiation is the sialic acid-binding Ig-like lectin 15 (Siglec-15). Siglecs are a distinct group of the immunoglobulin superfamily that have evolved to use sialylated glycans as their predominant ligands. They are involved in the regulation of several immune cells in numerous pathologies including infectious diseases, inflammation, and cancer [101]. Siglec- 15 has been first described in macrophages and dendritic cells, but it is most strongly expressed in OCs and their precursors [102]. Mice lacking Siglec-15 show mild osteopetrosis and impaired OC differentiation, and Siglec- 15 antibodies reduce the fusion of murine OCs in vitro [102-104]. This function of Siglec-15 has been related to its intracellular association with the adaptor DAP12, a master actor of macrophage and OC fusion [105, 106], and Syk-dependent signaling that has been proposed to activate the RANK pathway [103]. The transcription factor(s) involved in Siglec15-mediated enhancement of osteoclastogenesis are not known. Siglec-15 and other Siglecs have specific extracellular domains that can interact with a huge variety of ligands both in cis and in trans, thus facilitating cell-to-cell interactions [107]. One of the Siglec-15 ligands is CD44 [108], and Siglec-15 expressed at the surface of OC precursors could recognize CD44 on adjacent OC precursors to either trigger downstream signaling via DAP12 [109] or simply help to bring membranes together. Recently, Siglec-15, as well as Siglec-1/CD169, have been associated with pulmonary tuberculosis $[110,111]$. The presence of these Siglecs, along with other Siglec proteins, at the surface of lung macrophages could also participate in the formation of MGCs in $M t b$-induced granulomas.

\section{Adhesion receptors}

Integrins mediate cell-to-extracellular matrix and cell-tocell adhesion [112], hence they are potentially engaged in all steps of MGC formation. They are ubiquitous heterodimeric receptors composed of one $\alpha$ - and one $\beta$-subunits. They constitute a family of 24 members with specific tissue distribution and distinct ligand binding capacities. Expressed at the cell surface, integrins adopt a high-affinity state for ligand binding in processes defined as inside-out and outside-in signaling, and through their intracellular domains, they regulate actin cytoskeleton polymerization, among other pathways. In myeloid cells, the main adhesive structure is the podosome, which sticks to the extracellular matrix thanks to integrins and other adhesion receptors (see "Role of podosomes and zipper-like structures in myeloid cell fusion").

The best-characterized integrin expressed by OCs is $\alpha \mathrm{V} \beta 3$, which binds to a variety of extracellular matrix proteins such as vitronectin, osteopontin, and bone sialoprotein [112]. In vitro differentiated OCs from $\beta 3$ null mice had disorganized sealing zones and less nuclei. However, $\beta 3^{-/-}$mice develop an osteosclerotic phenotype with increased numbers of OCs. The bone phenotype of deficient mice is probably due to the impaired bone resorption activity of OCs [113], along with defects in the associated signaling pathways mediated by c-Src, Syk, and DAP12 [114]. $\beta 3$ integrin localizes in the diffuse actin cloud of the podosome structure and could participate in OC fusion along with another adhesion protein, CD44, which localizes to the 
podosome actin core [115]. In mammalian OCs, in addition to $\alpha \mathrm{V} \beta 3$, several other integrins are expressed, such as integrins $\beta 1, \beta 2$, and $\beta 5$. Different studies have highlighted the role of integrins $\alpha 9 \beta 1, \alpha \mathrm{M} \beta 2, \alpha \mathrm{L} \beta 2$, as well as $\alpha \mathrm{V} \beta 5$ in OC fusion and bone resorption activity in vitro. However, integrin heterogeneity and potential compensation render in vivo phenotypes of integrin $\mathrm{KO}$ mice difficult to interpret [116-120].

The activation of integrins depends on the binding of adapter proteins, namely Kindlin-3, Talin1 and Rap1; the role of these integrin regulators in osteoclastogenesis has been assessed using elegant mouse models developed by the teams of Moser, Ginsberg and Teitelbaum [121, 122]. Using either single, double, or triple integrin $\beta 1, \beta 2, \beta 3$-deficient OCs cultured in vitro, they first proved that only a double or triple integrin $\mathrm{KO}$ impaired podosome and sealing zone organization, suggesting compensatory functions between integrins. Interestingly, the phenotype of triple integrin $\mathrm{KO}$ OCs presents the same characteristics as kindlin $-3^{-/-}$OCs, specifically multinucleation is strongly impaired together with important defects in podosome organization. Moreover, kindlin-3 KO mice developed severe osteopetrosis, stronger than those of mice lacking the three integrins. Similar results were obtained with Talin1 and Rap1 KO mice [122]. Finally, the role of both $\beta 1$ and $\beta 2$ has also been studied in FBGCs by McNally and Anderson. Using anti-integrin $\beta 1$ and $\beta 2$ antibodies, they showed inhibition of FBGC adhesion and fusion [123]. Additionally, the ligand-receptor pair LFA-1/ICAM-1 was suggested to play a role in the fusion of MGCs in human blood monocytes cultured with cytokines IL2, IL-4, or TNF $\alpha$ [124], and in rat microglia cultured in vitro with IL-3, IL-4, gamma-INF, and GM-CSF [125].

In conclusion, although some of the results depend on the experimental model, integrins clearly play an important role in cell-matrix and cell-to-cell adhesion as well as cytoskeletal rearrangement during MGC formation. However, it is still difficult to clarify which sets of integrins control each of the stages of MGC fusion and function.

CD44 is a ubiquitous cell surface adhesion molecule involved in both cell-matrix and cell-to-cell interactions. Expressed in many cell types, including myeloid and lymphoid cells, this transmembrane protein recognizes and binds to numerous components of the extracellular matrix such as hyaluronic acid, collagens, osteopontin, and laminins [126]. CD44 is transiently induced in macrophages under fusogenic conditions, and CD44 ligands prevent multinucleation, suggesting that CD44 and its putative ligands participate in adhesion/fusion mechanisms [127]. However, the impact of CD44 deficiency on the formation of OCs remains unclear [128, 129]. While CD44 specific-antibodies inhibit fusion in primary bone marrow-derived OCs [130], no bone defects were observed in vivo for $\mathrm{CD} 44 \mathrm{KO}$ mice under physiological conditions, suggesting that in these conditions, compensating signals may exist for the loss of CD44 [128]. However, CD44 deficiency does suppress cortical bone defects induced by hindlimb unloading [129]. Thus, in vitro, CD44 appears to be involved in OC formation but its role in OC differentiation and function in vivo seems to be only revealed in some induced-bone loss models and could be strongly dependent on the pathological context.

Cadherins are transmembrane glycoproteins that mediate $\mathrm{Ca}^{2+}$-dependent cell-to-cell adhesion. E-cadherin is the best-characterized component of cell junctions, which contributes to the maintenance of the epithelial barrier integrity through homotypic interactions [131]. E-cadherin is also expressed in the monocyte/macrophage lineage. It is induced in a STAT- 6 dependent manner consequently to IL-4 or IL-13 treatments [44, 105, 132, 133]. In IL-4 stimulated macrophages, E-cadherin forms complexes with catenins that accumulate at the sites of cell contact [133, 134]. Different approaches using treatment with specific antibodies and E-cadherin-deficient macrophages show that this protein participates through homotypic interaction in IL-4-induced MGC formation [44, 133]. E-cadherin is also involved in the OC fusion process, as blocking E-cadherin in 1,25 dihydroxyvitamin $\mathrm{D}_{3}$ - stimulated bone marrow cells significantly reduces both the number of multinucleated OCs and bone resorption activity [135]. This effect was confirmed in RANKL-treated RAW 264.7 macrophage cells, in which inhibition of E-cadherin impairs OC fusion and delays early stages of osteoclastogenesis [136]. It is also interesting to note that E-cadherin could be involved in heterotypic interactions and, potentially, heterotypic fusion [133], in particular between macrophages and $\mathrm{T}$ cells.

Connexins are a multigene family of hemichannel- and gap junction-forming proteins. Connexin-43 (Cx43) is the major connexin protein expressed in developing and mature skeletal tissues. This protein is abundant in OCs and OC precursors in mouse and human [25, 137-139]. So far, little is known about the precise function of gap-junction proteins in OC formation, but blocking gap-junctional communication and particularly $\mathrm{Cx} 43$ inhibits $\mathrm{OC}$ fusion and bone resorption in vitro [137-139]. In mice, Cx43 is required for both skeletal development and maintenance, particularly in cortical bone. However, because $\mathrm{Cx} 43$ is expressed and functional in a wide variety of bone cells, including OCs, osteoblasts and osteocytes, these skeletal phenotypes remain difficult to interpret $[140,141]$. While Cx43 involvement in OC fusion has been proposed but not fully understood [141], some studies also proposed a role for gap junctions in the fusion of myeloid cells (FBGCs) based on immunohistochemistry and ultrastructural immunogold labelling showing that $\mathrm{Cx} 43$ localizes between fusing macrophages $[142,143]$. In addition, with a lower expression level in OCs compared to $\mathrm{Cx} 43, \mathrm{Cx} 37$ has also been recently described 
to participate in $\mathrm{OC}$ fusion and differentiation both in vitro and in vivo, with higher bone density in $\mathrm{Cx} 37 \mathrm{KO}$ mice compared to controls [144]. Thus, further studies are needed to better understand the role of the different connexins in MGC formation.

\section{Other cell-surface receptors}

The signal regulatory protein $\alpha$ (SIRP $\alpha)$ also known as MFR (Macrophage fusion receptor) was one of the first molecules implicated in macrophage fusion. This transmembrane glycoprotein of the superfamily of immunoglobulins possesses a cytoplasmic tail containing multiple ITIMs and is highly expressed in myeloid cells. Its interaction with the integrinassociated transmembrane protein CD47 is essential for adhesion leading to macrophage multinucleation and to $\mathrm{OC}$ fusion both in vitro and in vivo [145-150]. Moreover, during osteoclastogenesis, disruption of the CD47-SIRP $\alpha$ association leads to a lack of SIRP $\alpha$ phosphorylation, a defect in Src homology 2 domain-containing protein tyrosine phosphatase (SHP) recruitment, and impaired dephosphorylation (i.e., impaired inhibition) of the non-muscle actin-based motor myosin IIA (MyoIIA) [151]. This is consistent with the transient decrease of MyoIIA expression required to trigger OC fusion [152]. It is important to note that in addition to its interaction in trans with SIRP $\alpha$, CD47 can also bind in cis a set of integrins and the extracellular matrix glycoprotein, thrombospondin-1 (TSP-1) [153]. For example, in concert with the cell-surface protein CD36 (see below), CD47 also participates in TSP1-mediated OC formation [154]. In addition to this complexity, Podolnikova et al. recently reported that the macrophage integrin 1 antigen (Mac-1) also interacts in cis with CD47, becoming another ligand of SIRP $\alpha$ in trans, and that their interaction could be involved in macrophage fusion [155]. In contrast to the myeloid restricted expression of SIRP $\alpha$, CD47 is widely and variably expressed in all types of cells. Its interaction with SIRP $\alpha$ transmits an anti-phagocytic signal to macrophages, known as the "don't eat me" signal that protects cells from macrophage engulfment. In many cancer cells and in immune cells during infection, CD47 is upregulated, allowing the cells to evade innate immune detection [156-158]. If we consider the active role of the SIRP $\alpha / C D 47$ axis in the fusion process between two myeloid cells, we assume that this interaction triggers two mechanisms: first, it inhibits phagocytosis of the target cell by macrophages; and second, it promotes the fusion of this target cell with macrophages, giving rise to heterotypic or homotypic giant cells. Hence, regulating the expression of SIRP $\alpha / C D 47$ might be of pivotal importance to control MGC formation and survival.
Using an unbiased antibody screening strategy to identify mediators of macrophage fusion induced by IL-4, Helming et $a l$. identified the class B scavenger receptor CD36 [159]. CD36 (also known as platelet glycoprotein 4) is a membrane receptor with an extensively glycosylated extracellular domain flanked by two transmembrane domains. It is expressed in a variety of cell types and binds a diverse array of ligands, including oxidized low-density lipoproteins, nonopsonized bacteria, and ligands on apoptotic cells. As a molecule specialized in sensing and internalizing lipids, the role of CD36 at the surface of macrophages has been mainly described to mediate foam cell formation in atherosclerosis [160]. In the context of MGC formation, CD36 is necessary for IL-4-mediated murine macrophage fusion in vitro via the recognition of phosphatidylserine exposed at the membrane of the target cell before membrane merging [159]. The role of this protein in OC fusion is not obvious [154, 159], but CD36 could cooperate with CD47 as mentioned before [154]. It is likely that the role of CD36 in OC fusion could also involve its interaction with phosphatidylserine on OC precursors, as osteoclastogenesis has been shown to be controlled by the phosphatidylserine-regulated activity of several proteins in an in vitro model of synchronized fusion of OC precursors [161].

Tetraspanins constitute a large family of four-pass transmembrane proteins, which are ubiquitously expressed. Through their association with numerous partners, including integrins, cytoskeletal proteins, and signaling molecules, tetraspanins organize specialized membrane microdomains (tetraspanin-enriched microdomains) and participate in many biological processes including cell adhesion, migration, and different types of cell-to-cell fusion [162]. Tetraspanins, such as CD9 and CD81, are required for muscleand sperm-egg fusion mechanisms [163]. In contrast, when stimulated in vitro or in vivo, alveolar macrophages and bone marrow cells of CD9- and CD81-KO mice form more MGCs compared to $w t$, and double-null mice spontaneously develop MGCs in the lung [164]. This inhibitory role of CD9 and CD81 in phagocyte fusion has also been supported in an experimental system using Concanavalin A-induced fusion, while in this model, another tetraspanin, CD63, promoted MGC formation [164-166]. The role of tetraspanins in OC fusion is more controversial. Bone marrow cells from CD9-null mice stimulated in vitro display enhanced OC fusion, and CD9 and CD81 double null mice show increased $\mathrm{OC}$ number associated with a loss in bone mineral density [164]. In contrast, CD9 inhibition by siRNA or blocking antibodies reduces fusion in vitro [167]. More recently, other tetraspanins, such as CD82, have also been reported to regulate OC fusion [168]. Thus, due to their 
partner multiplicity, their heterogeneity, and their involvement in numerous biological functions beyond cell-to-cell fusion, the roles of tetraspanins in myeloid cells still remain elusive.

\section{Fusogenic proteins}

Fusogenic proteins induce the merging of two lipid membranes. Today, syncytins are the only fusogenic proteins implicated in the fusion of myeloid cells. They are composed of syncytin-1 and -2 in humans [169], and syncytin-A and -B in mice [170, 171]. Although the murine and human syncytin genes are not orthologous, they are all derived from retroviral genes that have been stably integrated in the mammalian genome [172]. These viral envelope proteins are involved in several physiological processes of cell-tocell fusion such as the formation of the syncytiotrophoblasts [169] or the fusion of myoblasts into myotubes [173], upon interaction with ASCT-2 [169]. The role of syncytins in OC multinucleation has been investigated in both humans and mice. In humans, syncytin- 1 is transiently expressed at early stages of OC differentiation [24, 36, 174], whereas the expression of its receptor ASCT- 2 is enhanced at early steps and remains stable [36]. Inhibition of syncytin-1 blocks fusion of OCs in the early stages with no impact on OC number $[13,36]$. Furthermore, this inhibition has no effect on bone degradation activity by mature OCs [36]. Interestingly, in human OCs, syncytin-1 co-localizes with F-actin in podosomes and filopodia and then concentrates in the contact zone when the two partners are in close proximity [36]. In mice, a comparison between syncytin $\mathrm{B}^{-/-}$and $w t$ OCs differentiated ex vivo shows that syncytin B plays a role in the fusion of OCs at initial stages but it does not seem essential for bone resorption activity. In agreement with these in vitro observations, syncytin-B-deficient mice show a normal bone phenotype [24]. The effect of syncytin in myeloid cell fusion is not limited to OCs since there is an inhibition in the number of IL4-derived multinucleated cells from the bone marrow of syncytin-B deficient mice compared to $w t$. However, these mice did not show any change in the number of FBGCs formed in response to implanted foreign material [24]. The role of syncytins in the fusion of myeloid cells in different contexts is consistent with the fact that syncytin expression is not dependent on RANKL signaling [36] and thus not restricted to OCs. Although it is clear that syncytins are involved in several contexts of myeloid cell fusion, further work is needed to reconcile the different observations. Importantly, it appears that altering syncytin function in OCs inhibits their capacity to fuse but not to degrade bone matrices, suggesting that these two criteria may not be systematically dependent on each other [13].

\section{Role of podosomes and zipper-like structures in myeloid cell fusion}

Cellular fusion is a multistage process, and each step appears to rely on the actin cytoskeleton. Live-cell imaging has uncovered a variety of actin-based structures between fusion partners but their precise roles remain to be identified. Podosomes, particularly prominent in cells of the monocytic lineage such as macrophages, dendritic cells, and OCs, are multifunctional F-actin structures that combine several key abilities required in particular for cell migration and invasion [175-177]. The podosome function repertoire includes well-established functions such as cell-substrate adhesion, degradation of the extracellular matrix, and rigidity and topography sensing [176, 177], but were also proposed to be involved in cell protrusion stabilization, cell migration in 3D environments and cell-to-cell fusion [176, 178-180]. Podosomes present a submicron-size core of Arp2/3-mediated branched F-actin and actin-regulatory proteins, including WASP and cortactin. This core is surrounded by an adhesion ring comprising integrins and proteins linking integrins to the actin cytoskeleton, such as vinculin and talin. Podosomes are dynamic entities forming the basis of different structures depending on cell types and differentiation stages. In OCs, podosomes are collectively and sequentially organized into different high-ordered structures along the lifespan and activity of the cells and the properties of the matrix: clusters, rings, podosome belts, and sealing zones [16, 29, $101,180,181]$, the latter being the functional structure confining bone resorption [182].

Zipper-like structures, which are also podosome-related structures, have been described recently at the initial stages of cell-to-cell adhesion in keratinocytes [183] and during the fusion of myoblasts into myotubes [1]. Their name comes from the periodic actin distribution that resembles a zipper. In contrast to other actin structures present in individual cells and responsible for cell-matrix interactions, the zipperlike structures are involved in cell-to-cell interactions. This transient structure exhibits the unique ability to bridge two plasma membranes. The present paragraph discusses the role of podosomes or podosome-like structures in the process of myeloid cell fusion, particularly during osteoclastogenesis and IL-4 induced MGCs (FBGC formation).

Two studies first revealed the presence and the role of podosome-like structures in the fusion of OCs [184, 185]. Zipper-like structures were observed during OC fusion in the murine macrophage cell line RAW 264.7 and in OCs derived from mouse bone marrow macrophages. It is important to note that complete OC differentiation is the result of a combination of fusions involving heterotypic precursors with sometimes different numbers of nuclei 
[29]. In addition to podosome-like structures observed at early steps of OC fusion that could be the origin of the podosome belts in mature OCs, later stages of fusion (e.g., fusion of multinucleated cells) involve canonical zipperlike structures formed at the cell contact sites followed by fusion of the podosome belts and finally apposition of the plasma membrane $[185,186]$. The actin flow in the zipper-like structure is proposed to generate forces that facilitate adhesion between multinucleated partner cells. In addition, in the center of these structures, the plasma membranes of the two partner cells form close contact sites where membrane fusion would be promoted [29, 185 , 186]. Importantly, zipper-like structures have also been observed in vitro, in OCs derived from chicken bone marrow cells [187] and in vivo in OC found in mouse calvariae [185].

Several proteins of podosomes are present in zipper-like structures of OCs. For example, Arp2/3 and cortactin colocalize with actin at the center of the zipper-like structures, whereas integrin $\beta 3$, paxillin, vinculin, and zyxin localize to the periphery of the structure $[185,188]$. As for podosome formation in primary macrophages, zipper-like structure formation is dependent on Tks5, a Src substrate [189], and its stability is affected by Arp2/3 inhibition [184, 188]. In addition, MyoIIA-mediated actin contractility seems to be an inhibitory checkpoint for cell fusion in several contexts [1], including OC multinucleation [152]. However, inhibition of myosin light chain kinase with ML-7 has shown little effect on zipper-like structure organization [188], suggesting that zipper-like structure formation is rather mediated by branched actin elongation than by actomyosin contraction.

To our knowledge, the involvement of the molecular actors of cell-to-cell fusion found in podosomes (CD44, E-cadherin, integrins; see "Different types of multinucleated giant cells from the monocytic lineage" and Table 1) in zipper-like structure formation or stability has not been examined. Of note, most of the studies describing the role of podosome-like structures in OC fusion have been performed in mouse mainly using the RAW 264.7 cell line. It could be important to decipher the mechanisms of zipperlike structure formation and dynamics in more physiological OC models.

A recent and elegant study demonstrated the existence of zipper-like structures in FBGCs. Indeed, this study revealed zipper-like structures that arise between mouse MGCs induced by IL-4 stimulation in vitro and following biomaterial implantation in vivo [134]. Using live imaging and super-resolution microscopy, the group of Ugarova showed that podosomes are the precursors of these zipper-like structures. As a consequence, and similarly to OC zipper-like structures described above, these zipperlike structures contain many podosome proteins, and their assembly and stability are dependent on Arp2/3, Wasp, and
Cdc42. Furthermore, they found that the junctional protein E-cadherin and SIRP $\alpha$ localize at the intercellular space between adjacent cell membranes within zipper-like structures[134]. Interestingly, these two proteins have been linked to macrophage fusion (see "Molecular actors involved in cell-to-cell fusion"). From these data, it can be proposed that these structures are not involved in early cell fusions of IL-4-derived MGCs because zipper-like structures appeared at late stages of the fusion process. However, it is likely that they stabilize the adhesion of multinucleated cells, suppressing migration and/or inducing proteolysis, and thus participating in the later stages of fusion.

Although zipper-like structures described in OCs and in FBGCs share similar features in terms of morphology, dynamics, and association with podosome components, they may have different functions and thus require further analysis.

\section{Tunneling nanotubes and myeloid cell fusion}

In addition to zipper-like structures, alternative structures, including filopodium-like protrusions, may also participate in the fusion process $[29,186,190]$. These structures show a morphological similarity to so-called TNTs [191-193]. For the past 15 years, TNTs have received scientific attention as a type of intercellular communication machinery. They form particularly between myeloid cells (macrophages, OCs, and dendritic cells). The identification of TNTs was a crucial turning point in the research field of intercellular communication as they possess the capacity to transfer cytoplasmic molecules, proteins, organelles and even pathogens between cells. This ability constitutes the main functional criterion for TNT definition. Some TNTs are closed, that could form a gap junction between the tip of the protrusion and the targeted cell (close-ended TNTs) [194]. Alternatively, closed TNTs could be immature ones before they fuse with the acceptor cell (open-ended TNTs). Here, for simplicity reasons, we will use the word TNTs for both closed- and openended structures.

In macrophages, TNTs have been classified into two types with different functions: thin TNTs (diameter of less than $5 \mu \mathrm{m}$ ), containing only F-actin; and thick TNTs, which contain both actin and microtubules (diameter ranging from 5 to $20 \mu \mathrm{m})[111,195-197]$. Only thick TNTs are able to transport large organelles such as lysosomes, mitochondria, and even, albeit questionably, nuclei [198].

During human or murine OC fusion, it has been observed that OC precursors form abundant TNTs prior to cell-tocell fusion $[31,195,199,200]$ that resemble the thick and thin TNTs described in macrophages. A role of TNTs in the fusion process has been suggested [195, 199, 200], 
potentially to help in fusion partner rapprochement. M-Sec has been identified as a key factor in macrophage TNT formation [195, 201, 202]. Consistent with this, the expression level of M-Sec increases during osteoclastogenesis, and M-Sec depletion significantly suppresses OC differentiation and fusion [95, 199]. Furthermore, there is now evidence of intercellular transport of DC-STAMP through TNTs formed between OC precursors [95]. In addition, large TNTs may provide a route for nuclei transport during OC fusion [198].

Myosin X (MyoX) is a molecular motor that utilizes ATP to perform many cellular functions, including TNT formation and elongation between neuronal cells [203]. This unconventional myosin is also expressed in OCs [200]. Mice with MyoX loss of function exhibit osteoporotic defects, which are likely due to increased osteoclastogenesis and bone resorption as bone formation markers were unchanged [204]. This in vivo phenotype is in contradiction with in vitro observations. Actually, in addition to defects in F-actin organization (i.e., sealing zone formation) and adhesion of mature OCs, OC precursors with reduced levels of MyoX expression by an shRNA approach remained mononucleated and unable to fuse. These results were correlated with a significant decrease in TNT formation in the absence of MyoX. Surprisingly, this effect is independent of $\mathrm{M}-\mathrm{sec}$ expression, suggesting another potential mechanism for TNT-mediated OC fusion [200]. In addition, the presence of heterotypic TNTs between endothelial progenitor cells and $\mathrm{OC}$ precursors boosts OC fusion. Although these structures do not induce heterotypic fusion, they could indirectly permit OC precursors to acquire fusogenic capacity [205].

Despite a lack of functional assays, filopodium-like protrusions have been described during the fusion of FBGCs in vitro [190]. Long intercellular F-actin structures (up to a few hundred microns) could be a way for a fusion-competent cell to identify a distant fusion partner. In addition, once the two cells are in close proximity, thin and short actin protrusions (around ten microns) emerging from the leading-edge of the cells are observed [190]. Interestingly, protrusions originate from sites that are enriched in podosomes which could play a role in the stabilization of cell-to-cell adhesion and, more hypothetically, in the fusion of the two interconnected cells. These two types of actin protrusions could be the TNT-like structures observed during OC fusion [29, 185].

Another potential role for TNTs in cell-to-cell fusion concerns HIV-1 infection of macrophages [111, 197, 206, 207], which are prone to form MGCs (see "Introduction"). In this context, we revealed a correlation between the formation of TNTs at the early stages of HIV-1 infection of human macrophages and the extent of the fusion later on [57, 111, 195, 197, 208]. In terms of molecular actors, M-Sec mediates rapid and efficient cell-to-cell transmission of HIV-1 at an early phase of infection by enhancing both cell motility, TNT formation, and number of nuclei per infected macrophages [207]. Finally, Cx43 localizes at the tip of close-ended TNTs formed between HIV-infected macrophages, suggesting that stabilization of long-range gap junction-dependent communication could favor HIV-1 transfer [206]. In this context, the specific role of TNTs in macrophage fusion has not been examined, nor the relevance of closed- and open-ended TNTs in pathogen spread [195]. HIV-1 transfer from infected CD4 T cells to macrophages is also mediated by a fusion mechanism, however, whether heterotypic TNTs form during this process is not known.

Despite remarkable advances in TNT biology over the last decade, formidable challenges in this discipline remain, including TNT function, heterogeneity, and existence in vivo. TNT structures seem much more versatile than zipper-like structures. They are morphologically heterogeneous and expressed at early but also at late stages of macrophage fusion. It is clear that TNTs mediate continuity between remote cells for cargo transport, and thus could transport proteins or signaling molecules involved in cell-tocell fusion. In addition, it is likely that TNTs and zipper-like structures exert physical forces that bring the two connected cells closer together and promote their fusion. The molecular components driving cell-to-cell fusion and the existence of TNTs in vivo also need to be examined. Many questions still remain, in particular, further investigation is required to determine the structural similarities between TNTs and zipper-like structures and the contribution of these two F-actin structures in cell-to-cell fusion process [186, 209]. Some studies in the literature suggest a differential involvement of these structures depending on the type of MGCs and/or the stage of the fusion process.

\section{Perspectives}

The fusion of myeloid cells is a hallmark of osteoclastogenesis but it is also involved in numerous pathologies. However, the gain in the function of multinucleation is still an enigma. In the particular case of OCs, the efficiency of fusion usually correlates with bone resorption activity, and deregulation in the number of nuclei leads to bone diseases, such as osteopetrosis or Paget's disease, suggesting that the physiological cell-to-cell fusion process must be strictly controlled [30, 31, 33, 93]. Regarding the other MGCs, they are generally associated with pathological conditions and most have exacerbated functions. Therefore, it is of interest to be able to control their formation and for that, it is necessary to better understand their fusion mechanisms. Although not universal, the molecular machinery involved in the fusion process seems to be shared, at least partially, between OCs and MGCs in different contexts (Fig. 1). However, some specificities exist in the nature of the molecular actors and 
the actin-based structures involved, depending on the type of MGCs and the stage of the cell-to-cell fusion process. There are still significant gaps in the characterization of the molecular determinants required for MGC formation.

An interesting avenue of research would be to take advantage of these specificities and identify fusion molecules or structures specifically linked to discrete MGC-associated diseases. The identification of specific markers could considerably advance the diagnosis of these diseases and lead to the discovery of new drugs with a more controlled impact. Moreover, most of the fusion molecules identified so far promote or stabilize the fusion process, and only a few, i.e., tetraspanins, have been identified as fusion inhibitors. It would be interesting to study whether these proteins, in a physiological context, are sufficient to limit the natural fusogenic capacity of myeloid cells and prevent macrophages from fusing with their counterparts or with other cell types. Looking for new inhibitory actors of the fusion process could also help to better understand how, under fusogenic conditions, this inhibition could be bypassed.

Another objective will be to develop robust models to study MGC formation, especially in vivo. Indeed, most of the studies have been performed in vitro, and in vivo approaches often fail to show similar effects. Although the in vitro models, generally limited to a single cell type cultured at high density, provide valuable information for the identification of critical actors in macrophage fusion, they could bias the choice of the F-actin structures involved. For example, at an advanced stage of OC differentiation, the proximity of MGCs will favor the formation of zipper-like structures with the emergence of fine TNT-type structures that induce the fusion process $[29,95,134]$; the presence of these structures still needs to be demonstrated on a relevant substrate, such as bone matrix for OCs, and in more complex three-dimensional settings. In addition, the existence of TNTs in vivo is still a matter of debate in the field, and has never been described in the bone environment. Finally, the quite recent concept of heterogeneity in the two fusion partners should be considered in future investigations of new actors in MGC formation.

In conclusion, important gaps still exist in our understanding of the mechanisms of myeloid cell fusion. The identification of specific actors in MGC formation will be important for identifying either markers or potential targets for MGC-associated pathologies.

Author contributions OD, RM, BRM, and CV equally participated in the conception and the redaction. IMP and RP gave advice on proofreading. All authors read and approved the final manuscript. Correspondence to $\mathrm{CV}$ or BRM.

Funding We thank Helen Pickersgill from Life Science Editors for english language editing of the manuscript and helpful comments. This work was supported by the Centre National de la Recherche Scientifique, the Agence Nationale de la Recherche, the Agence Nationale de Recherche sur le Sida et les hépatites virales and the Fondation pour la Recherche Médicale. OD is supported by Paul Sabatier University, Toulouse, France, and RM by Fondation Toulouse Cancer Santé, Toulouse, France and Fondation pour la Recherche Médicale (FRM).

Availability of data and materials Not applicable.

Code availability Not applicable.

\section{Declarations}

Conflict of interest The authors declare that they have no competing interests.

Ethical approval Not applicable.

Open Access This article is licensed under a Creative Commons Attribution 4.0 International License, which permits use, sharing, adaptation, distribution and reproduction in any medium or format, as long as you give appropriate credit to the original author(s) and the source, provide a link to the Creative Commons licence, and indicate if changes were made. The images or other third party material in this article are included in the article's Creative Commons licence, unless indicated otherwise in a credit line to the material. If material is not included in the article's Creative Commons licence and your intended use is not permitted by statutory regulation or exceeds the permitted use, you will need to obtain permission directly from the copyright holder. To view a copy of this licence, visit http://creativecommons.org/licenses/by/4.0/.

\section{References}

1. Kim JH, Chen EH (2019) The fusogenic synapse at a glance. J Cell Sci. https://doi.org/10.1242/jcs.213124

2. Helming L, Gordon S (2007) The molecular basis of macrophage fusion. Immunobiology 212:785-793

3. Pereira M, Petretto E, Gordon S, Bassett JHD, Williams GR, Behmoaras J (2018) Common signalling pathways in macrophage and osteoclast multinucleation. J Cell Sci. https://doi. org/10.1242/jcs. 216267

4. Anderson JM, Rodriguez A, Chang DT (2008) Foreign body reaction to biomaterials. Semin Immunol 20:86-100

5. Brodbeck WG, Anderson JM (2009) Giant cell formation and function. Curr Opin Hematol 16:53-57

6. Brooks PJ, Glogauer M, McCulloch CA (2019) An overview of the derivation and function of multinucleated giant cells and their role in pathologic processes. Am J Pathol 189:1145-1158

7. Helming L, Gordon S (2009) Molecular mediators of macrophage fusion. Trends Cell Biol. https://doi.org/10.1016/j.tcb. 2009.07.005

8. Willenbring H, Bailey AS, Foster M, Akkari Y, Dorrell C, Olson S, Finegold M, Fleming WH, Grompe M (2004) Myelomonocytic cells are sufficient for therapeutic cell fusion in liver. Nat Med 10:744-748

9. Manjunath Y, Porciani D, Mitchem JB, Suvilesh KN, Avella DM, Kimchi ET, Staveley-O'Carroll KF, Burke DH, Li G, Kaifi JT (2020) Tumor-cell-macrophage fusion cells as liquid biomarkers and tumor enhancers in cancer. Int J Mol Sci. https://doi.org/10. 3390/ijms 21051872 
10. Shabo I, Svanvik J, Lindstrom A, Lechertier T, Trabulo S, Hulit J, Sparey T, Pawelek J (2020) Roles of cell fusion, hybridization and polyploid cell formation in cancer metastasis. World J Clin Oncol 11:121-135

11. Bracq L, Xie M, Benichou S, Bouchet J (2018) Mechanisms for cell-to-cell transmission of HIV-1. Front Immunol 9:260

12. Bracq L, Xie M, Lambele M, Vu LT, Matz J, Schmitt A, Delon J, Zhou P, Randriamampita C, Bouchet J et al (2017) T cell-macrophage fusion triggers multinucleated giant cell formation for HIV-1 spreading. J Virol. https://doi.org/10.1128/JVI.01237-17

13. Moller AM, Delaisse JM, Soe K (2017) Osteoclast fusion: timelapse reveals involvement of CD47 and syncytin-1 at different stages of nuclearity. J Cell Physiol 232:1396-1403

14. Soe K (2020) Osteoclast fusion: physiological regulation of multinucleation through heterogeneity-potential implications for drug sensitivity. Int J Mol Sci. https://doi.org/10.3390/ijms21207717

15. Feng X, Teitelbaum SL (2013) Osteoclasts: new insights. Bone Res 1:11-26

16. Georgess D, Machuca-Gayet I, Blangy A, Jurdic P (2014) Podosome organization drives osteoclast-mediated bone resorption. Cell Adhes Migr 8:191-204

17. Yasuda H, Shima N, Nakagawa N, Yamaguchi K, Kinosaki M, Mochizuki S, Tomoyasu A, Yano K, Goto M, Murakami A et al (1998) Osteoclast differentiation factor is a ligand for osteoprotegerin/osteoclastogenesis-inhibitory factor and is identical to TRANCE/RANKL. Proc Natl Acad Sci USA 95:3597-3602

18. Nakashima $T$, Takayanagi $H$ (2011) New regulation mechanisms of osteoclast differentiation. Ann NY Acad Sci 1240:E13-18

19. Teitelbaum SL (2000) Bone resorption by osteoclasts. Science 289:1504-1508

20. Teitelbaum SL (2011) The osteoclast and its unique cytoskeleton. Ann NY Acad Sci 1240:14-17

21. Soe K, Delaisse JM (2017) Time-lapse reveals that osteoclasts can move across the bone surface while resorbing. J Cell Sci 130:2026-2035

22. Jacome-Galarza CE, Percin GI, Muller JT, Mass E, Lazarov T, Eitler J, Rauner M, Yadav VK, Crozet L, Bohm M et al (2019) Developmental origin, functional maintenance and genetic rescue of osteoclasts. Nature 568:541-545

23. Soe K, Hobolt-Pedersen AS, Delaisse JM (2015) The elementary fusion modalities of osteoclasts. Bone 73:181-189

24. Coudert AE, Redelsperger F, Chabbi-Achengli Y, Vernochet C, Marty C, Decrouy X, Heidmann T, de Vernejoul MC, Dupressoir A (2019) Role of the captured retroviral envelope syncytin-B gene in the fusion of osteoclast and giant cell precursors and in bone resorption, analyzed ex vivo and in vivo in syncytin-B knockout mice. Bone Rep 11:100214

25. Hobolt-Pedersen AS, Delaisse JM, Soe K (2014) Osteoclast fusion is based on heterogeneity between fusion partners. Calcif Tissue Int 95:73-82

26. Mbalaviele G, Novack DV, Schett G, Teitelbaum SL (2017) Inflammatory osteolysis: a conspiracy against bone. J Clin Investig 127:2030-2039

27. Moller AMJ, Delaisse JM, Olesen JB, Madsen JS, Canto LM, Bechmann T, Rogatto SR, Soe K (2020) Aging and menopause reprogram osteoclast precursors for aggressive bone resorption. Bone Res 8:27

28. Piper K, Boyde A, Jones SJ (1992) The relationship between the number of nuclei of an osteoclast and its resorptive capability in vitro. Anat Embryol (Berl) 186:291-299

29. Takito J, Nakamura M (2020) Heterogeneity and actin cytoskeleton in osteoclast and macrophage multinucleation. Int J Mol Sci. https://doi.org/10.3390/ijms21186629

30. Galson DL, Roodman GD (2014) Pathobiology of Paget's disease of bone. J Bone Metab 21:85-98
31. Raynaud-Messina B, Bracq L, Dupont M, Souriant S, Usmani SM, Proag A, Pingris K, Soldan V, Thibault C, Capilla F et al (2018) Bone degradation machinery of osteoclasts: an HIV-1 target that contributes to bone loss. Proc Natl Acad Sci USA 115:E2556-E2565

32. Gohda J, al., e. (2015) HIV-1 replicates in human osteoclasts and enhances their differentiation in vitro. Retrovirology 12:12

33. Raynaud-Messina B, Verollet C, Maridonneau-Parini I (2019) The osteoclast, a target cell for microorganisms. Bone 127:315-323

34. Trouillet-Assant S, Gallet M, Nauroy P, Rasigade JP, Flammier S, Parroche P, Marvel J, Ferry T, Vandenesch F, Jurdic P et al (2015) Dual impact of live Staphylococcus aureus on the osteoclast lineage, leading to increased bone resorption. J Infect Dis 211:571-581

35. Miyamoto H, Suzuki T, Miyauchi Y, Iwasaki R, Kobayashi T, Sato Y, Miyamoto K, Hoshi H, Hashimoto K, Yoshida S et al (2012) Osteoclast stimulatory transmembrane protein and dendritic cell-specific transmembrane protein cooperatively modulate cell-cell fusion to form osteoclasts and foreign body giant cells. J Bone Miner Res 27:1289-1297

36. Soe K, Andersen TL, Hobolt-Pedersen AS, Bjerregaard B, Larsson LI, Delaisse JM (2011) Involvement of human endogenous retroviral syncytin-1 in human osteoclast fusion. Bone 48:837-846

37. McNally AK, Anderson JM (1995) Interleukin-4 induces foreign body giant cells from human monocytes/macrophages. Differential lymphokine regulation of macrophage fusion leads to morphological variants of multinucleated giant cells. Am J Pathol 147:1487-1499

38. McNally AK, Anderson JM (2011) Foreign body-type multinucleated giant cells induced by interleukin-4 express select lymphocyte co-stimulatory molecules and are phenotypically distinct from osteoclasts and dendritic cells. Exp Mol Pathol 91:673-681

39. Khan UA, Hashimi SM, Khan S, Quan J, Bakr MM, Forwood MR, Morrison NM (2014) Differential expression of chemokines, chemokine receptors and proteinases by foreign body giant cells (FBGCs) and osteoclasts. J Cell Biochem 115:1290-1298

40. Miron RJ, Zohdi H, Fujioka-Kobayashi M, Bosshardt DD (2016) Giant cells around bone biomaterials: Osteoclasts or multi-nucleated giant cells? Acta Biomater 46:15-28

41. Trout KL, Holian A (2020) Multinucleated giant cell phenotype in response to stimulation. Immunobiology 225:151952

42. McNally AK, Anderson JM (2015) Phenotypic expression in human monocyte-derived interleukin-4-induced foreign body giant cells and macrophages in vitro: dependence on material surface properties. J Biomed Mater Res A 103:1380-1390

43. Milde R, Ritter J, Tennent GA, Loesch A, Martinez FO, Gordon S, Pepys MB, Verschoor A, Helming L (2015) Multinucleated giant cells are specialized for complement-mediated phagocytosis and large target destruction. Cell Rep 13:1937-1948

44. Moreno JL, Mikhailenko I, Tondravi MM, Keegan AD (2007) IL-4 promotes the formation of multinucleated giant cells from macrophage precursors by a STAT6-dependent, homotypic mechanism: contribution of E-cadherin. J Leukoc Biol 82:1542-1553

45. da Costa CE, Annels NE, Faaij CM, Forsyth RG, Hogendoorn PC, Egeler RM (2005) Presence of osteoclast-like multinucleated giant cells in the bone and nonostotic lesions of Langerhans cell histiocytosis. J Exp Med 201:687-693

46. Okamoto H, Mizuno K, Horio T (2003) Monocyte-derived multinucleated giant cells and sarcoidosis. J Dermatol Sci 31:119-128

47. Boros DL (1989) Immunopathology of Schistosoma mansoni infection. Clin Microbiol Rev 2:250-269 
48. Russell DG, Cardona PJ, Kim MJ, Allain S, Altare F (2009) Foamy macrophages and the progression of the human tuberculosis granuloma. Nat Immunol 10:943-948

49. Herrtwich L, Nanda I, Evangelou K, Nikolova T, Horn V, Sagar ED, Stefanowski J, Rogell L, Klein C et al (2016) DNA damage signaling instructs polyploid macrophage fate in granulomas. Cell 167:1264-1280 e1218

50. Sakai H, Okafuji I, Nishikomori R, Abe J, Izawa K, Kambe N, Yasumi T, Nakahata T, Heike T (2012) The CD40-CD40L axis and IFN-gamma play critical roles in Langhans giant cell formation. Int Immunol 24:5-15

51. Puissegur MP, Lay G, Gilleron M, Botella L, Nigou J, Marrakchi H, Mari B, Duteyrat JL, Guerardel Y, Kremer L et al (2007) Mycobacterial lipomannan induces granuloma macrophage fusion via a TLR2-dependent, ADAM9- and beta1 integrinmediated pathway. J Immunol 178:3161-3169

52. Guirado E, Schlesinger LS, Kaplan G (2013) Macrophages in tuberculosis: friend or foe. Semin Immunopathol 35:563-583

53. Lay G, Poquet Y, Salek-Peyron P, Puissegur MP, Botanch C, Bon H, Levillain F, Duteyrat JL, Emile JF, Altare F (2007) Langhans giant cells from $M$. tuberculosis-induced human granulomas cannot mediate mycobacterial uptake. J Pathol 211:76-85

54. Gharun K, Senges J, Seidl M, Losslein A, Kolter J, Lohrmann F, Fliegauf M, Elgizouli M, Alber M, Vavra M et al (2017) Mycobacteria exploit nitric oxide-induced transformation of macrophages into permissive giant cells. EMBO Rep 18:2144-2159

55. Zhu XW, Price NM, Gilman RH, Recarvarren S, Friedland JS (2007) Multinucleate giant cells release functionally unopposed matrix metalloproteinase-9 in vitro and in vivo. J Infect Dis 196:1076-1079

56. Sattentau Q (2008) Avoiding the void: cell-to-cell spread of human viruses. Nat Rev Microbiol 6:815-826

57. Dupont M, Sattentau QJ (2020) Macrophage cell-cell interactions promoting HIV-1 infection. Viruses. https://doi.org/10. 3390/v12050492

58. Leroy H, Han M, Woottum M, Bracq L, Bouchet J, Xie M, Benichou S (2020) Virus-mediated cell-cell fusion. Int J Mol Sci. https://doi.org/10.3390/ijms21249644

59. Lifson JD, Feinberg MB, Reyes GR, Rabin L, Banapour B, Chakrabarti S, Moss B, Wong-Staal F, Steimer KS, Engleman EG (1986) Induction of CD4-dependent cell fusion by the HTLVIII/LAV envelope glycoprotein. Nature 323:725-728

60. Verollet C, Souriant S, Bonnaud E, Jolicoeur P, RaynaudMessina B, Kinnaer C, Fourquaux I, Imle A, Benichou S, Fackler OT et al (2015) HIV-1 reprograms the migration of macrophages. Blood 125:1611-1622

61. Verollet C, Zhang YM, Le Cabec V, Mazzolini J, Charriere G, Labrousse A, Bouchet J, Medina I, Biessen E, Niedergang F et al (2010) HIV-1 Nef triggers macrophage fusion in a p61Hck- and protease-dependent manner. J Immunol 184:7030-7039

62. Frankel SS, Wenig BM, Burke AP, Mannan P, Thompson LD, Abbondanzo SL, Nelson AM, Pope M, Steinman RM (1996) Replication of HIV-1 in dendritic cell-derived syncytia at the mucosal surface of the adenoid. Science 272:115-117

63. Lewin-Smith M, Wahl SM, Orenstein JM (1999) Human immunodeficiency virus-rich multinucleated giant cells in the colon: a case report with transmission electron microscopy, immunohistochemistry, and in situ hybridization. Mod Pathol 12:75-81

64. Koenig S, Gendelman HE, Orenstein JM, Dal Canto MC, Pezeshkpour GH, Yungbluth M, Janotta F, Aksamit A, Martin MA, Fauci AS (1986) Detection of AIDS virus in macrophages in brain tissue from AIDS patients with encephalopathy. Science 233:1089-1093

65. Mascarau R, Bertrand F, Labrousse A, Gennero I, Poincloux R, Maridonneau-Parini I, Raynaud-Messina B, Verollet C (2020) HIV-1-infected human macrophages, by secreting RANK-L, contribute to enhanced osteoclast recruitment. Int J Mol Sci. https://doi.org/10.3390/ijms21093154

66. Xu Y, Kulkosky J, Acheampong E, Nunnari G, Sullivan J, Pomerantz RJ (2004) HIV-1-mediated apoptosis of neuronal cells: Proximal molecular mechanisms of HIV-1-induced encephalopathy. Proc Natl Acad Sci USA 101:7070-7075

67. Compton AA, Schwartz O (2017) They might be giants: does syncytium formation sink or spread HIV infection? PLoS Pathog 13:e1006099

68. Boliar S, Gludish DW, Jambo KC, Kamng'ona R, Mvaya L, Mwandumba HC, Russell DG (2019) Inhibition of the lncRNA SAF drives activation of apoptotic effector caspases in HIV1-infected human macrophages. Proc Natl Acad Sci USA 116:7431-7438

69. Clayton KL, Collins DR, Lengieza J, Ghebremichael M, Dotiwala F, Lieberman J, Walker BD (2018) Resistance of HIV-infected macrophages to $\mathrm{CD} 8(+) \mathrm{T}$ lymphocyte-mediated killing drives activation of the immune system. Nat Immunol 19:475-486

70. Honeycutt JB, Thayer WO, Baker CE, Ribeiro RM, Lada SM, Cao Y, Cleary RA, Hudgens MG, Richman DD, Garcia JV (2017) HIV persistence in tissue macrophages of humanized myeloid-only mice during antiretroviral therapy. Nat Med. https://doi.org/10.1038/nm.4319

71. Sattentau QJ, Stevenson M (2016) Macrophages and HIV-1: an unhealthy constellation. Cell Host Microbe 19:304-310

72. Castellano P, Prevedel L, Eugenin EA (2017) HIV-infected macrophages and microglia that survive acute infection become viral reservoirs by a mechanism involving Bim. Sci Rep 7:12866

73. Kruize Z, Kootstra NA (2019) The role of macrophages in HIV-1 persistence and pathogenesis. Front Microbiol 10:2828

74. Xie M, Leroy H, Mascarau R, Woottum M, Dupont M, Ciccone C, Schmitt A, Raynaud-Messina B, Verollet C, Bouchet J et al (2019) Cell-to-cell spreading of HIV-1 in myeloid target cells escapes SAMHD1 restriction. MBio. https://doi.org/10.1128/ mBio.02457-19

75. Granelli-Piperno A, Pope M, Inaba K, Steinman RM (1995) Coexpression of NF-kappa B/Rel and Sp1 transcription factors in human immunodeficiency virus 1-induced, dendritic cell-Tcell syncytia. Proc Natl Acad Sci USA 92:10944-10948

76. Pope M, Betjes MG, Romani N, Hirmand H, Cameron PU, Hoffman L, Gezelter S, Schuler G, Steinman RM (1994) Conjugates of dendritic cells and memory T lymphocytes from skin facilitate productive infection with HIV-1. Cell 78:389-398

77. Calantone N, Wu F, Klase Z, Deleage C, Perkins M, Matsuda K, Thompson EA, Ortiz AM, Vinton CL, Ourmanov I et al (2014) Tissue myeloid cells in SIV-infected primates acquire viral DNA through phagocytosis of infected T cells. Immunity 41:493-502

78. DiNapoli SR, Ortiz AM, Wu F, Matsuda K, Twigg HL 3rd, Hirsch VM, Knox K, Brenchley JM (2017) Tissue-resident macrophages can contain replication-competent virus in antiretroviral-naïve, SIV-infected Asian macaques. JCI Insight 2:214

79. Martinez-Mendez D, Rivera-Toledo E, Ortega E, Licona-Limon I, Huerta L (2017) Monocyte-lymphocyte fusion induced by the HIV-1 envelope generates functional heterokaryons with an activated monocyte-like phenotype. Exp Cell Res 352:9-19

80. Crowe SM, Mills J, Kirihara J, Boothman J, Marshall JA, McGrath MS (1990) Full-length recombinant CD4 and recombinant gp120 inhibit fusion between HIV infected macrophages and uninfected CD4-expressing T-lymphoblastoid cells. AIDS Res Hum Retrovir 6:1031-1037

81. Burleigh L, Lozach PY, Schiffer C, Staropoli I, Pezo V, Porrot F, Canque B, Virelizier JL, Arenzana-Seisdedos F, Amara A (2006) Infection of dendritic cells (DCs), not DC-SIGN-mediated internalization of human immunodeficiency virus, is required for long-term transfer of virus to T cells. J Virol 80:2949-2957 
82. Duncan CJ, Williams JP, Schiffner T, Gartner K, Ochsenbauer C, Kappes J, Russell RA, Frater J, Sattentau QJ (2014) Highmultiplicity HIV-1 infection and neutralizing antibody evasion mediated by the macrophage-T cell virological synapse. J Virol 88:2025-2034

83. Groot F, Welsch S, Sattentau QJ (2008) Efficient HIV-1 transmission from macrophages to $\mathrm{T}$ cells across transient virological synapses. Blood 111:4660-4663

84. Zhang C, Dou CE, Xu J, Dong S (2014) DC-STAMP, the key fusion-mediating molecule in osteoclastogenesis. J Cell Physiol 229:1330-1335

85. Hartgers FC, Vissers JL, Looman MW, van Zoelen C, Huffine C, Figdor CG, Adema GJ (2000) DC-STAMP, a novel multimembrane-spanning molecule preferentially expressed by dendritic cells. Eur J Immunol 30:3585-3590

86. Staege H, Brauchlin A, Schoedon G, Schaffner A (2001) Two novel genes FIND and LIND differentially expressed in deactivated and Listeria-infected human macrophages. Immunogenetics 53:105-113

87. Islam R, Bae HS, Yoon WJ, Woo KM, Baek JH, Kim HH, Uchida T, Ryoo HM (2014) Pin1 regulates osteoclast fusion through suppression of the master regulator of cell fusion DC-STAMP. J Cell Physiol 229:2166-2174

88. Yagi M, Miyamoto T, Sawatani Y, Iwamoto K, Hosogane N, Fujita N, Morita K, Ninomiya K, Suzuki T, Miyamoto K et al (2005) DC-STAMP is essential for cell-cell fusion in osteoclasts and foreign body giant cells. J Exp Med 202:345-351

89. Chiu YH, Schwarz E, Li D, Xu Y, Sheu TR, Li J, de Mesy Bentley KL, Feng C, Wang B, Wang JC et al (2017) Dendritic cell-specific transmembrane protein (DC-STAMP) regulates osteoclast differentiation via the $\mathrm{Ca}(2+) / \mathrm{NFATc} 1$ axis. J Cell Physiol 232:2538-2549

90. Kim K, Lee SH, Ha Kim J, Choi Y, Kim N (2008) NFATc1 induces osteoclast fusion via up-regulation of Atp6v0d2 and the dendritic cell-specific transmembrane protein (DCSTAMP). Mol Endocrinol 22:176-185

91. Miyamoto H, Katsuyama E, Miyauchi Y, Hoshi H, Miyamoto $\mathrm{K}$, Sato Y, Kobayashi T, Iwasaki R, Yoshida S, Mori T et al (2012) An essential role for STAT6-STAT1 protein signaling in promoting macrophage cell-cell fusion. J Biol Chem 287:32479-32484

92. Yagi M, Ninomiya K, Fujita N, Suzuki T, Iwasaki R, Morita K, Hosogane N, Matsuo K, Toyama Y, Suda T et al (2007) Induction of DC-STAMP by alternative activation and downstream signaling mechanisms. J Bone Miner Res 22:992-1001

93. Kodama J, Kaito T (2020) Osteoclast multinucleation: review of current literature. Int J Mol Sci. https://doi.org/10.3390/ijms2 1165685

94. Mensah KA, Ritchlin CT, Schwarz EM (2010) RANKL induces heterogeneous DC-STAMP(lo) and DC-STAMP(hi) osteoclast precursors of which the DC-STAMP(lo) precursors are the master fusogens. J Cell Physiol 223:76-83

95. Takahashi A, Kukita A, Li YJ, Zhang JQ, Nomiyama H, Yamaza T, Ayukawa Y, Koyano K, Kukita T (2013) Tunneling nanotube formation is essential for the regulation of osteoclastogenesis. $\mathrm{J}$ Cell Biochem 114:1238-1247

96. Yang M, Birnbaum MJ, MacKay CA, Mason-Savas A, Thompson B, Odgren PR (2008) Osteoclast stimulatory transmembrane protein (OC-STAMP), a novel protein induced by RANKL that promotes osteoclast differentiation. J Cell Physiol 215:497-505

97. Witwicka H, Hwang SY, Reyes-Gutierrez P, Jia H, Odgren PE, Donahue LR, Birnbaum MJ, Odgren PR (2015) Studies of OCSTAMP in osteoclast fusion: a new knockout mouse model, rescue of cell fusion, and transmembrane topology. PLoS ONE 10:e0128275
98. Ishii T, Ruiz-Torruella M, Ikeda A, Shindo S, Movila A, Mawardi H, Albassam A, Kayal RA, Al-Dharrab AA, Egashira K et al (2018) OC-STAMP promotes osteoclast fusion for pathogenic bone resorption in periodontitis via up-regulation of permissive fusogen CD9. FASEB J 32:4016-4030

99. Khan UA, Hashimi SM, Bakr MM, Forwood MR, Morrison NA (2013) Foreign body giant cells and osteoclasts are TRAP positive, have podosome-belts and both require OC-STAMP for cell fusion. J Cell Biochem 114:1772-1778

100. Miyamoto T (2013) STATs and macrophage fusion. JAKSTAT 2:e24777

101. Macauley MS, Crocker PR, Paulson JC (2014) Siglec-mediated regulation of immune cell function in disease. Nat Rev Immunol 14:653-666

102. Hiruma Y, Hirai T, Tsuda E (2011) Siglec-15, a member of the sialic acid-binding lectin, is a novel regulator for osteoclast differentiation. Biochem Biophys Res Commun 409:424-429

103. Ishida-Kitagawa N, Tanaka K, Bao X, Kimura T, Miura T, Kitaoka Y, Hayashi K, Sato M, Maruoka M, Ogawa T et al (2012) Siglec-15 protein regulates formation of functional osteoclasts in concert with DNAX-activating protein of $12 \mathrm{kDa}$ (DAP12). J Biol Chem 287:17493-17502

104. Hiruma Y, Tsuda E, Maeda N, Okada A, Kabasawa N, Miyamoto M, Hattori H, Fukuda C (2013) Impaired osteoclast differentiation and function and mild osteopetrosis development in Siglec15-deficient mice. Bone 53:87-93

105. Helming L, Tomasello E, Kyriakides TR, Martinez FO, Takai $\mathrm{T}$, Gordon S, Vivier E (2008) Essential role of DAP12 signaling in macrophage programming into a fusion-competent state. Sci Signal 1:ra11

106. Zou W, Teitelbaum SL (2015) Absence of Dap12 and the alphavbeta3 integrin causes severe osteopetrosis. J Cell Biol 208:125-136

107. Brown GD, Crocker PR (2016) Lectin receptors expressed on myeloid cells. Microbiol Spectr. https://doi.org/10.1128/micro biolspec.MCHD-0036-2016

108. Chang L, Chen YJ, Fan CY, Tang CJ, Chen YH, Low PY, Ventura A, Lin CC, Chen YJ, Angata T (2017) Identification of siglec ligands using a proximity labeling method. J Proteome Res 16:3929-3941

109. Angata T (2020) Siglec-15: a potential regulator of osteoporosis, cancer, and infectious diseases. J Biomed Sci 27:10

110. Bhattacharyya C, Majumder PP, Pandit B (2019) An exome wide association study of pulmonary tuberculosis patients and their asymptomatic household contacts. Infect Genet Evol 71:76-81

111. Dupont M, Souriant S, Balboa L, Vu Manh TP, Pingris K, Rousset S, Cougoule C, Rombouts Y, Poincloux R, Ben Neji M et al (2020) Tuberculosis-associated IFN-I induces Siglec-1 on tunneling nanotubes and favors HIV-1 spread in macrophages. Elife. https://doi.org/10.7554/eLife.52535

112. Shattil SJ, Kim C, Ginsberg MH (2010) The final steps of integrin activation: the end game. Nat Rev Mol Cell Biol 11:288-300

113. McHugh KP, Hodivala-Dilke K, Zheng MH, Namba N, Lam J, Novack D, Feng X, Ross FP, Hynes RO, Teitelbaum SL (2000) Mice lacking beta3 integrins are osteosclerotic because of dysfunctional osteoclasts. J Clin Investig 105:433-440

114. Zou W, Kitaura H, Reeve J, Long F, Tybulewicz VL, Shattil SJ, Ginsberg MH, Ross FP, Teitelbaum SL (2007) Syk, c-Src, the alphavbeta3 integrin, and ITAM immunoreceptors, in concert, regulate osteoclastic bone resorption. J Cell Biol 176:877-888

115. Chabadel A, Banon-Rodriguez I, Cluet D, Rudkin BB, WehrleHaller B, Genot E, Jurdic P, Anton IM, Saltel F (2007) CD44 and beta3 integrin organize two functionally distinct actin-based domains in osteoclasts. Mol Biol Cell 18:4899-4910 
116. Bloemen V, de Vries TJ, Schoenmaker T, Everts V (2009) Intercellular adhesion molecule-1 clusters during osteoclastogenesis. Biochem Biophys Res Commun 385:640-645

117. Garcia-Palacios V, Chung HY, Choi SJ, Sarmasik A, Kurihara N, Lee JW, Galson DL, Collins R, Roodman GD (2007) Eosinophil chemotactic factor-L (ECF-L) enhances osteoclast formation by increasing in osteoclast precursors expression of LFA-1 and ICAM-1. Bone 40:316-322

118. Lane NE, Yao W, Nakamura MC, Humphrey MB, Kimmel D, Huang X, Sheppard D, Ross FP, Teitelbaum SL (2005) Mice lacking the integrin beta5 subunit have accelerated osteoclast maturation and increased activity in the estrogen-deficient state. J Bone Miner Res 20:58-66

119. Rao H, Lu G, Kajiya H, Garcia-Palacios V, Kurihara N, Anderson J, Patrene K, Sheppard D, Blair HC, Windle JJ et al (2006) Alpha9beta1: a novel osteoclast integrin that regulates osteoclast formation and function. J Bone Miner Res 21:1657-1665

120. Sprangers S, Schoenmaker T, Cao Y, Everts V, de Vries TJ (2017) Integrin alphaMbeta2 is differently expressed by subsets of human osteoclast precursors and mediates adhesion of classical monocytes to bone. Exp Cell Res 350:161-168

121. Schmidt S, Nakchbandi I, Ruppert R, Kawelke N, Hess MW, Pfaller K, Jurdic P, Fassler R, Moser M (2011) Kindlin-3-mediated signaling from multiple integrin classes is required for osteoclast-mediated bone resorption. J Cell Biol 192:883-897

122. Zou W, Izawa T, Zhu T, Chappel J, Otero K, Monkley SJ, Critchley DR, Petrich BG, Morozov A, Ginsberg MH et al (2013) Talin1 and Rap1 are critical for osteoclast function. Mol Cell Biol 33:830-844

123. McNally AK, Anderson JM (2002) Beta1 and beta2 integrins mediate adhesion during macrophage fusion and multinucleated foreign body giant cell formation. Am J Pathol 160:621-630

124. Most J, Neumayer HP, Dierich MP (1990) Cytokine-induced generation of multinucleated giant cells in vitro requires interferongamma and expression of LFA-1. Eur J Immunol 20:1661-1667

125. Lee TT, Martin FC, Merrill JE (1993) Lymphokine induction of rat microglia multinucleated giant cell formation. Glia 8:51-61

126. Ponta H, Sherman L, Herrlich PA (2003) CD44: from adhesion molecules to signalling regulators. Nat Rev Mol Cell Biol 4:33-45

127. Sterling H, Saginario C, Vignery A (1998) CD44 occupancy prevents macrophage multinucleation. J Cell Biol 143:837-847

128. de Vries TJ, Schoenmaker T, Beertsen W, van der Neut R, Everts $\mathrm{V}$ (2005) Effect of CD44 deficiency on in vitro and in vivo osteoclast formation. J Cell Biochem 94:954-966

129. Li Y, Zhong G, Sun W, Zhao C, Zhang P, Song J, Zhao D, Jin X, Li Q, Ling S et al (2015) CD44 deficiency inhibits unloadinginduced cortical bone loss through downregulation of osteoclast activity. Sci Rep 5:16124

130. Kania JR, Kehat-Stadler T, Kupfer SR (1997) CD44 antibodies inhibit osteoclast formation. J Bone Miner Res 12:1155-1164

131. van Roy F, Berx G (2008) The cell-cell adhesion molecule E-cadherin. Cell Mol Life Sci 65:3756-3788

132. Rehli M, Sulzbacher S, Pape S, Ravasi T, Wells CA, Heinz S, Sollner L, El Chartouni C, Krause SW, Steingrimsson E et al (2005) Transcription factor Tfec contributes to the IL-4-inducible expression of a small group of genes in mouse macrophages including the granulocyte colony-stimulating factor receptor. $\mathrm{J}$ Immunol 174:7111-7122

133. Van den Bossche J, Bogaert P, van Hengel J, Guerin CJ, Berx G, Movahedi K, Van den Bergh R, Pereira-Fernandes A, Geuns JM, Pircher $\mathrm{H}$ et al (2009) Alternatively activated macrophages engage in homotypic and heterotypic interactions through IL-4 and polyamine-induced E-cadherin/catenin complexes. Blood $114: 4664-4674$
134. Balabiyev A, Podolnikova NP, Mursalimov A, Lowry D, Newbern JM, Roberson RW, Ugarova TP (2020) Transition of podosomes into zipper-like structures in macrophage-derived multinucleated giant cells. Mol Biol Cell 31:2002-2020

135. Mbalaviele G, Chen H, Boyce BF, Mundy GR, Yoneda T (1995) The role of cadherin in the generation of multinucleated osteoclasts from mononuclear precursors in murine marrow. J Clin Investig 95:2757-2765

136. Fiorino C, Harrison RE (2016) E-cadherin is important for cell differentiation during osteoclastogenesis. Bone 86:106-118

137. Ilvesaro J, Vaananen K, Tuukkanen J (2000) Bone-resorbing osteoclasts contain gap-junctional connexin-43. J Bone Miner Res 15:919-926

138. Kylmaoja E, Kokkonen H, Kauppinen K, Hussar P, Sato T, Haugan K, Larsen BD, Tuukkanen J (2013) Osteoclastogenesis is influenced by modulation of gap junctional communication with antiarrhythmic peptides. Calcif Tissue Int 92:270-281

139. Schilling AF, Filke S, Lange T, Gebauer M, Brink S, Baranowsky A, Zustin J, Amling M (2008) Gap junctional communication in human osteoclasts in vitro and in vivo. J Cell Mol Med 12:2497-2504

140. Moorer MC, Stains JP (2017) Connexin43 and the intercellular signaling network regulating skeletal remodeling. Curr Osteoporos Rep 15:24-31

141. Zappitelli T, Aubin JE (2014) The "connexin" between bone cells and skeletal functions. J Cell Biochem 115:1646-1658

142. Herde K, Hartmann S, Brehm R, Kilian O, Heiss C, Hild A, Alt V, Bergmann M, Schnettler R, Wenisch S (2007) Connexin 43 expression of foreign body giant cells after implantation of nanoparticulate hydroxyapatite. Biomaterials 28:4912-4921

143. Wenisch S, Cavalcanti-Adam EA, Tryankowski E, Raabe O, Kilian O, Heiss C, Alt V, Arnhold S, Schnettler R (2012) Light- and transmission-electron-microscopic investigations on distribution of CD44, connexin 43 and actin cytoskeleton during the foreign body reaction to a nanoparticular hydroxyapatite in mini-pigs. Acta Biomater 8:2807-2814

144. Pacheco-Costa R, Hassan I, Reginato RD, Davis HM, Bruzzaniti A, Allen MR, Plotkin LI (2014) High bone mass in mice lacking $\mathrm{Cx} 37$ because of defective osteoclast differentiation. J Biol Chem 289:8508-8520

145. Han X, Sterling H, Chen Y, Saginario C, Brown EJ, Frazier WA, Lindberg FP, Vignery A (2000) CD47, a ligand for the macrophage fusion receptor, participates in macrophage multinucleation. J Biol Chem 275:37984-37992

146. Koskinen C, Persson E, Baldock P, Stenberg A, Bostrom I, Matozaki T, Oldenborg PA, Lundberg P (2013) Lack of CD47 impairs bone cell differentiation and results in an osteopenic phenotype in vivo due to impaired signal regulatory protein alpha (SIRPalpha) signaling. J Biol Chem 288:29333-29344

147. Lundberg P, Koskinen C, Baldock PA, Lothgren H, Stenberg A, Lerner UH, Oldenborg PA (2007) Osteoclast formation is strongly reduced both in vivo and in vitro in the absence of CD47/SIRPalpha-interaction. Biochem Biophys Res Commun 352:444-448

148. Saginario C, Qian HY, Vignery A (1995) Identification of an inducible surface molecule specific to fusing macrophages. Proc Natl Acad Sci USA 92:12210-12214

149. Vernon-Wilson EF, Kee WJ, Willis AC, Barclay AN, Simmons DL, Brown MH (2000) CD47 is a ligand for rat macrophage membrane signal regulatory protein SIRP (OX41) and human SIRPalpha 1. Eur J Immunol 30:2130-2137

150. Vignery A (2005) Macrophage fusion: the making of osteoclasts and giant cells. J Exp Med 202:337-340

151. Maile LA, DeMambro VE, Wai C, Lotinun S, Aday AW, Capps BE, Beamer WG, Rosen CJ, Clemmons DR (2011) An 
essential role for the association of CD47 to SHPS-1 in skeletal remodeling. J Bone Miner Res 26:2068-2081

152. McMichael BK, Wysolmerski RB, Lee BS (2009) Regulated proteolysis of nonmuscle myosin IIA stimulates osteoclast fusion. J Biol Chem 284:12266-12275

153. Oldenborg PA (2013) CD47: A cell surface glycoprotein which regulates multiple functions of hematopoietic cells in health and disease. ISRN Hematol 2013:614619

154. Koduru SV, Sun BH, Walker JM, Zhu M, Simpson C, Dhodapkar M, Insogna KL (2018) The contribution of crosstalk between the cell-surface proteins CD36 and CD47TSP-1 in osteoclast formation and function. J Biol Chem 293:15055-15069

155. Podolnikova NP, Hlavackova M, Wu Y, Yakubenko VP, Faust J, Balabiyev A, Wang X, Ugarova TP (2019) Interaction between the integrin Mac-1 and signal regulatory protein alpha (SIRPalpha) mediates fusion in heterologous cells. J Biol Chem 294:7833-7849

156. Chao MP, Weissman IL, Majeti R (2012) The CD47-SIRPalpha pathway in cancer immune evasion and potential therapeutic implications. Curr Opin Immunol 24:225-232

157. Jaiswal S, Jamieson CH, Pang WW, Park CY, Chao MP, Majeti $\mathrm{R}$, Traver D, van Rooijen N, Weissman IL (2009) CD47 is upregulated on circulating hematopoietic stem cells and leukemia cells to avoid phagocytosis. Cell 138:271-285

158. Morrissey MA, Kern N, Vale RD (2020) CD47 ligation repositions the inhibitory receptor SIRPA to suppress integrin activation and phagocytosis. Immunity 53:290-302 e296

159. Helming L, Winter J, Gordon S (2009) The scavenger receptor CD36 plays a role in cytokine-induced macrophage fusion. J Cell Sci 122:453-459

160. Choromanska B, Mysliwiec P, Choromanska K, Dadan J, Chabowski A (2017) The role of CD36 receptor in the pathogenesis of atherosclerosis. Adv Clin Exp Med 26:717-722

161. Verma SK, Leikina E, Melikov K, Gebert C, Kram V, Young MF, Uygur B, Chernomordik LV (2018) Cell-surface phosphatidylserine regulates osteoclast precursor fusion. J Biol Chem 293:254-270

162. Hemler ME (2005) Tetraspanin functions and associated microdomains. Nat Rev Mol Cell Biol 6:801-811

163. Fanaei M, Monk PN, Partridge LJ (2011) The role of tetraspanins in fusion. Biochem Soc Trans 39:524-528

164. Takeda Y, Tachibana I, Miyado K, Kobayashi M, Miyazaki T, Funakoshi T, Kimura H, Yamane H, Saito Y, Goto H et al (2003) Tetraspanins CD9 and CD81 function to prevent the fusion of mononuclear phagocytes. J Cell Biol 161:945-956

165. Hulme RS, Higginbottom A, Palmer J, Partridge LJ, Monk PN (2014) Distinct regions of the large extracellular domain of tetraspanin CD9 are involved in the control of human multinucleated giant cell formation. PLoS ONE 9:e116289

166. Parthasarathy V, Martin F, Higginbottom A, Murray H, Moseley GW, Read RC, Mal G, Hulme R, Monk PN, Partridge LJ (2009) Distinct roles for tetraspanins CD9, CD63 and CD81 in the formation of multinucleated giant cells. Immunology 127:237-248

167. Ishii M, Iwai K, Koike M, Ohshima S, Kudo-Tanaka E, Ishii T, Mima T, Katada Y, Miyatake K, Uchiyama Y et al (2006) RANKL-induced expression of tetraspanin CD9 in lipid raft membrane microdomain is essential for cell fusion during osteoclastogenesis. J Bone Miner Res 21:965-976

168. Bergsma A, Ganguly SS, Wiegand ME, Dick D, Williams BO, Miranti CK (2019) Regulation of cytoskeleton and adhesion signaling in osteoclasts by tetraspanin CD82. Bone Rep 10:100196

169. Blond JL, Lavillette D, Cheynet V, Bouton O, Oriol G, ChapelFernandes S, Mandrand B, Mallet F, Cosset FL (2000) An envelope glycoprotein of the human endogenous retrovirus HERV-W is expressed in the human placenta and fuses cells expressing the type D mammalian retrovirus receptor. J Virol 74:3321-3329

170. Dupressoir A, Vernochet C, Bawa O, Harper F, Pierron G, Opolon P, Heidmann T (2009) Syncytin-A knockout mice demonstrate the critical role in placentation of a fusogenic, endogenous retrovirus-derived, envelope gene. Proc Natl Acad Sci USA 106:12127-12132

171. Dupressoir A, Vernochet C, Harper F, Guegan J, Dessen P, Pierron G, Heidmann T (2011) A pair of co-opted retroviral envelope syncytin genes is required for formation of the twolayered murine placental syncytiotrophoblast. Proc Natl Acad Sci USA 108:E1164-1173

172. Mi S, Lee X, Li X, Veldman GM, Finnerty H, Racie L, LaVallie E, Tang XY, Edouard P, Howes S et al (2000) Syncytin is a captive retroviral envelope protein involved in human placental morphogenesis. Nature 403:785-789

173. Redelsperger F, Raddi N, Bacquin A, Vernochet C, Mariot V, Gache V, Blanchard-Gutton N, Charrin S, Tiret L, Dumonceaux J et al (2016) Genetic evidence that captured retroviral envelope syncytins contribute to myoblast fusion and muscle sexual dimorphism in mice. PLoS Genet 12:e1006289

174. Amend SR, Torga G, Lin KC, Kostecka LG, de Marzo A, Austin RH, Pienta KJ (2019) Polyploid giant cancer cells: Unrecognized actuators of tumorigenesis, metastasis, and resistance. Prostate 79:1489-1497

175. Linder S, Kopp P (2005) Podosomes at a glance. J Cell Sci 118:2079-2082

176. van den Dries K, Linder S, Maridonneau-Parini I, Poincloux R (2019) Probing the mechanical landscape - new insights into podosome architecture and mechanics. J Cell Sci. https://doi.org/ $10.1242 /$ jcs. 236828

177. Wiesner C, Le-Cabec V, El Azzouzi K, Maridonneau-Parini I, Linder S (2014) Podosomes in space: macrophage migration and matrix degradation in 2D and 3D settings. Cell Adhes Migr $8: 179-191$

178. Luxenburg C, Addadi L, Geiger B (2006) The molecular dynamics of osteoclast adhesions. Eur J Cell Biol 85:203-211

179. Luxenburg C, Parsons JT, Addadi L, Geiger B (2006) Involvement of the Src-cortactin pathway in podosome formation and turnover during polarization of cultured osteoclasts. J Cell Sci 119:4878-4888

180. Saltel F, Chabadel A, Bonnelye E, Jurdic P (2008) Actin cytoskeletal organisation in osteoclasts: a model to decipher transmigration and matrix degradation. Eur J Cell Biol 87:459-468

181. Jurdic P, Saltel F, Chabadel A, Destaing O (2006) Podosome and sealing zone: specificity of the osteoclast model. Eur J Cell Biol 85:195-202

182. Takito J, Inoue S, Nakamura M (2018) The sealing zone in osteoclasts: a self-organized structure on the bone. Int J Mol Sci. https://doi.org/10.3390/ijms19040984

183. Vasioukhin V, Bauer C, Yin M, Fuchs E (2000) Directed actin polymerization is the driving force for epithelial cell-cell adhesion. Cell 100:209-219

184. Oikawa T, Oyama M, Kozuka-Hata H, Uehara S, Udagawa N, Saya H, Matsuo K (2012) Tks5-dependent formation of circumferential podosomes/invadopodia mediates cell-cell fusion. J Cell Biol 197:553-568

185. Takito J, Nakamura M, Yoda M, Tohmonda T, Uchikawa S, Horiuchi K, Toyama Y, Chiba K (2012) The transient appearance of zipper-like actin superstructures during the fusion of osteoclasts. J Cell Sci 125:662-672

186. Takito J, Nakamura M (2012) Precursors linked via the zipperlike structure or the filopodium during the secondary fusion of osteoclasts. Commun Integr Biol 5:453-457 
187. Wang D, Gu JH, Feng LL, Tong XS, Song RL, Zhao HY, Bian JC, Liu XZ, Yuan Y, Liu ZP (2018) 1-alpha,25-dihydroxyvitamin $\mathrm{D} 3$ potentiates avian osteoclast activation by increasing the formation of zipper-like structure via Src/Rac1 signaling. Biochem Biophys Res Commun 501:576-583

188. Takito J, Otsuka H, Inoue S, Kawashima T, Nakamura M (2017) Symmetrical retrograde actin flow in the actin fusion structure is involved in osteoclast fusion. Biol Open 6:1104-1114

189. Murphy DA, Courtneidge SA (2011) The "ins" and "outs" of podosomes and invadopodia: characteristics, formation and function. Nat Rev Mol Cell Biol 12:413-426

190. Faust JJ, Balabiyev A, Heddleston JM, Podolnikova NP, Baluch DP, Chew TL, Ugarova TP (2019) An actin-based protrusion originating from a podosome-enriched region initiates macrophage fusion. Mol Biol Cell 30:2254-2267

191. Ljubojevic N, Henderson JM, Zurzolo C (2020) The ways of actin: why tunneling nanotubes are unique cell protrusions. Trends Cell Biol. https://doi.org/10.1016/j.tcb.2020.11.008

192. McCoy-Simandle K, Hanna SJ, Cox D (2016) Exosomes and nanotubes: control of immune cell communication. Int J Biochem Cell Biol 71:44-54

193. Rustom A, Saffrich R, Markovic I, Walther P, Gerdes HH (2004) Nanotubular highways for intercellular organelle transport. Science 303:1007-1010

194. Wang X, Veruki ML, Bukoreshtliev NV, Hartveit E, Gerdes HH (2010) Animal cells connected by nanotubes can be electrically coupled through interposed gap-junction channels. Proc Natl Acad Sci USA 107:17194-17199

195. Dupont M, Souriant S, Lugo-Villarino G, Maridonneau-Parini I, Verollet C (2018) Tunneling nanotubes: intimate communication between myeloid cells. Front Immunol 9:43

196. Onfelt B, Nedvetzki S, Benninger RK, Purbhoo MA, Sowinski S, Hume AN, Seabra MC, Neil MA, French PM, Davis DM (2006) Structurally distinct membrane nanotubes between human macrophages support long-distance vesicular traffic or surfing of bacteria. J Immunol 177:8476-8483

197. Souriant S, Balboa L, Dupont M, Pingris K, Kviatcovsky D, Cougoule C, Lastrucci C, Bah A, Gasser R, Poincloux R et al (2019) Tuberculosis exacerbates HIV-1 infection through IL-10/STAT3dependent tunneling nanotube formation in macrophages. Cell Rep 26:3586-3599

198. Pennanen P, Alanne MH, Fazeli E, Deguchi T, Nareoja T, Peltonen S, Peltonen J (2017) Diversity of actin architecture in human osteoclasts: network of curved and branched actin supporting cell shape and intercellular micrometer-level tubes. Mol Cell Biochem 432:131-139
199. Kukita T, Takahashi A, Zhang JQ, Kukita A (2015) Membrane nanotube formation in osteoclastogenesis. Methods Mol Biol 1313:193-202

200. Tasca A, Astleford K, Lederman A, Jensen ED, Lee BS, Gopalakrishnan R, Mansky KC (2017) Regulation of Osteoclast Differentiation by Myosin X. Sci Rep 7:7603

201. Hanna SJ, McCoy-Simandle K, Leung E, Genna A, Condeelis J, Cox D (2019) Tunneling nanotubes, a novel mode of tumor cell-macrophage communication in tumor cell invasion. J Cell Sci. https://doi.org/10.1242/jcs.223321

202. Hase K, Kimura S, Takatsu H, Ohmae M, Kawano S, Kitamura H, Ito M, Watarai H, Hazelett CC, Yeaman C et al (2009) M-Sec promotes membrane nanotube formation by interacting with Ral and the exocyst complex. Nat Cell Biol 11:1427-1432

203. Gousset K, Marzo L, Commere PH, Zurzolo C (2013) Myo10 is a key regulator of TNT formation in neuronal cells. J Cell Sci 126:4424-4435

204. Wang B, Pan JX, Yu H, Xiong L, Zhao K, Xiong S, Guo JP, Lin S, Sun D, Zhao L et al (2019) Lack of myosin X enhances osteoclastogenesis and increases cell surface Unc5b in osteoclastlineage cells. J Bone Miner Res 34:939-954

205. Li RF, Zhang W, Man QW, Zhao YF, Zhao Y (2019) Tunneling nanotubes mediate intercellular communication between endothelial progenitor cells and osteoclast precursors. J Mol Histol 50:483-491

206. Okafo G, Prevedel L, Eugenin E (2017) Tunneling nanotubes (TNT) mediate long-range gap junctional communication: Implications for HIV cell to cell spread. Sci Rep 7:16660

207. Lotfi S, Nasser H, Noyori O, Hiyoshi M, Takeuchi H, Koyanagi Y, Suzu S (2020) M-Sec facilitates intercellular transmission of HIV-1 through multiple mechanisms. Retrovirology 17:20

208. Dupont M, Lugo-Villarino G, Verollet C (2020) The Siglec-1 receptor: bridging the infectious synergy between Mycobacterium tuberculosis and HIV-1. Med Sci (Paris) 36:855-858

209. Song RL, Liu XZ, Zhu JQ, Zhang JM, Gao Q, Zhao HY, Sheng AZ, Yuan Y, Gu JH, Zou H et al (2014) New roles of filopodia and podosomes in the differentiation and fusion process of osteoclasts. Genet Mol Res 13:4776-4787

Publisher's Note Springer Nature remains neutral with regard to jurisdictional claims in published maps and institutional affiliations. 